\title{
Contexto y determinantes funcionales de la clasificación documental
}

\author{
Francisco Javier García Marco \\ Facultad de Filosofía y Letras \\ Universidad de Zaragoza \\ E-50.009 Zaragoza \\ E-mail: jgarcia@posta.unizar.es
}

Oh What a tangled web we weave When first we practice to retrieve ...

(A C Foskett, 1982)

\subsection{Resumen}

La operación de clasificar es examinada en el contexto de la cadena documental. La clasificacion se define como una metodología heurística, que está siendo mejorada por la aplicación del método científico. Se considera una operación de indización, mediante la cual cada documento se sitúa en una ordenación sistemática, en la cual recibe un lugar predecible, y, por ello, puede ser recuperado eficazmente. La operación de clasificar aparece determinada por cuatro factores: a) la estructura del mundo de los documentos, una función a su vez de la estructura del mundo del conocimiento; b) los sistemas de clasificación que nos permiten codificar esas estructuras; c) el modo en que la gente construye y usa las clasificaciones; y d) las características de la unidad de información.

Palabras clave: Metodología de la Clasificación. Teoría de la Clasificación. Cadena documental.

\subsection{Abstract}

The classification process is considered in the frame of the information retrieval chain. a communication process. Classification is defined as an heuristic methodology, which is being improved through scientific methodology. It is also framed as an indexing process, setting each document in a systematic order, where it gets a predicible place and, therefore, can be efficiently retrieved. The classification activity appears determined by four factors: a) the structure of the world of documents, a function of the world of knowledge; b) the classifications tools that allow us to codify them; c) the way in which people create and use classifications;

Scire. 2 : 1 (en.-jun. 1996). 
and d) the features of the information unit. chain.

Keywords: Classification methodology. Classification theory. Documentary

\section{Conceptos previos}

\section{1. ¿Qué es clasificar?}

La clasificación no es sólo una operación fundamental en las bibiliotecas, en los archivos y en otros centros de información. La clasificación es un aspecto clave del comportamiento humano.

Las personas nos representamos el mundo exterior en estructuras de información que denominamos conocimientos, y gracias a ellas somos capaces de predecir la marcha de las cosas que pueden afectarnos, y actuar sobre nuestro entorno. En definitiva, gracias a esas estructuras o mapas cognitivos somos capaces de adaptarnos mejor.

La clasificación es, precisamente, la operación que rige la creación y organización de esas estructuras cognitivas equivalentes al mundo exterior, así como la asignación de nuevas entidades de dicho entorno a los esquemas ya creados haciendo posible que podamos pensar sobre esas estructuras y predecir el funcionamiento de nuestro ambiente.

La clasificación es, en último término, una estrategia para superar los límites de procesamiento de nuestra memoria de trabajo; límites que las investigaciones experimentales del psicólogo Miller (1956) fijaron en \pm 7 items. La operación de clasificar consiste precisamente en agrupar las unidades menores en unidades mayores (chunking), ampliando escalarmente en sucesivos niveles de abstracción nuestra capacidad de cálculo mental.

La clasificación añade a nuestro espacio mental una auténtica tercera dimensión que permite superar sus límites inmediatos. En el chunking (apiñamiento) se sitúan las raíces psicológicas de los procesos de clasificación y recodificación artificial, entre los que se cuentan las clasificaciones bibliográficas: Ante la enorme oferta de información que llega a nuestros sentidos y su carácter atómico, el sistema nervioso central procede a seleccionar y agrupar estímulos en virtud de su valor funcional (de cara a la supervivencia y autonomía del sistema humano) (Vid. García y Esteban, 1993; vid. infra). Fruto de ello, a lo largo de la historia evolutiva del individuo (ontogénesis) van surgiendo, desarrollándose e integrándose progresivamente una serie de esquemas representacionales neuronales que relacionan aspectos del mundo exterior con sensaciones, sentimientos, reflexiones y acciones del propio organismo. Muchos de esos esquemas, en realidad, los adquiere la persona de la propia cultura (sociogénesis) por medio del aprendiza-

Scire. 2 : 1 (en.-jun. 1996). 
je, mecanismo por medio del cual también somos capaces de integrar nuevos conocimientos en ella. En este contexto social, el aprendizaje simbólico — especialmente el lingüístico - se muestra superior al interactivo o al observacional por las posibilidades que ofrece al control reflexivo, fruto de su idiosincrásica función comunicativa e intersubjetiva. Con la evolución cultural, estos procesos internos y biológicos de recodificación condensativa resultaron extraordinaramiente potenciados por los documentos, esas memorias externas de trabajo y almacenamiento que han constituido el segundo gran avance cultural en el procesamiento humano de la información, a medio camino entre el lenguaje y las máquinas de procesamiento de información.

En definitiva, podemos afirmar sin escrúpulos que los procesos de conocimiento necesitan ineludiblemente de los procesos de clasificación. Sin embargo, esta dependencia queda muchas veces oculta por el hecho de que la mayor parte de las operaciones de clasificación quedan subsumidas en procesos de pensamiento más amplios y se realizan incluso de forma inconsciente, como ocurre en general en el uso cotidiano del lenguaje y en los procesos de percepción. El mismo hecho de utilizar una palabra para nombrar un objeto o un acontecimiento supone haber clasificado un conjunto de entidades semejantes, haber aislado sus propiedades definitorias, y aplicar ese modelo a cada nuevo objeto nombrable con dicho término. El lenguaje es, en definitiva, un enorme esquema de clasificación sin el cual difícilmente podríamos pensar. Además, en numerosas ocasiones, la clasificación es una actividad exenta y consciente. Esto ocurre especialmente en los procesos de organización y ordenación, que exigen una clasificación rigurosa y, a ser posible, cerrada. Así, por ejemplo, necesitamos una clasificación para ordenar una estantería, para organizar los útiles de una cocina, para estudiar los pobladores prehistóricos de España o para preparar un tema de Geografía para alumnos de Bachillerato.

\section{2.¿Qué es clasificar documentos?}

Un servicio de información no deja de ser un instrumento que facilita a sus usuarios la adquisición de información y, por tanto, de conocimientos. Por ello, desde un punto de vista meramente teórico y general, si la función del sistema de información es organizar dicha información para su recuperación eficaz, la clasificación ha de constituir también un apartado ineludible de su ciclo de vida. Por otro lado, sabemos que, en la práctica, los centros que organizan información clasifican, y que el proceso de generar y aplicar clasificaciones es una parte fundamental del trabajo que se lleva a cabo en ellos. Es casi imposible entender una biblioteca sin clasificar o un archivo sin su cuadro de clasificación. Incluso los centros que no mantienen fondos dependen de esas clasificaciones, por más que ellos mismos no clasifiquen y se dediquen meramente a la recuperación y a la

Scire. $2: 1$ (en.-jun. 1996). 


\section{2}

mediación en la adquisición de documentos primarios, como los centros de documentación.

Al hablar de clasificación en español, es necesario hacer una aclaración terminológica. Como habrá ya notado el lector la palabra clasificación se utiliza en español indistintamente para referirnos al proceso mismo de crear una clasificación, al producto de ese proceso o modelo con el que clasificamos, y al hecho de utilizar dicho esquema para clasificar un objeto o acontecimiento concreto. Es decir, por clasificación entendemos:

a) El proceso de analizar un conjunto de entidades para encontrar un sistema conceptual eficaz para organizarlas.

b) El producto del proceso anterior, que se denomina tablas o esquema de clasificación en las bibliotecas y unidades de documentación, y cuadros de clasificación en los archivos.

c) El proceso de aplicar un esquema de clasificación para resolver el problema concreto de qué lugar debe ocupar una entidad dada dentro del universo que estamos clasificando. Como señala la autorizada pluma de Maniez (1987, trad. esp. 1992, p. 23): "Clasificar es la operación intelectual por la cual el documentalista atribuye a una obra un índice correspondiente a una clase de materias, utilizando un lenguaje de clasificación (= una clasificación documental)" . Dicho proceso resulta en la asignación de un término denotador de la clase a la que pertenece dicho objeto denominado número de clasificación, y frecuentemente en nuestro país y el ámbito francófono, índice.

Paralelamente, es necesario señalar que el proceso de clasificación puede resultar en una organización de carácter físico o simplemente mediador y virtual. Es decir, la clasificación puede servir para disponer ordenadamente los ejemplares del fondo documental en los depósitos o, simplemente, para producir esos elementos mediadores del proceso de comunicación documental que denominamos catálogos, o listados bibliográficos sistemáticos como las bibliografías nacionales impresas.

Las acepciones a) y c) son operaciones distintas, y están bajo la responsabilidad de agentes distintos: Como señala Maniez (1992, p. 23): "Podemos distinguir fácilmente entre el clasificacionista (el que concibe y construye la clasificación) y el clasificador (el que clasifica)."

En este artículo nos vamos a ocupar precisamente de la acepción c) del concepto ‘clasificación'. Más en concreto, vamos a acometer la contextualización de la operación de clasificar dentro del proceso de comunicación documental desde tres puntos de vista:

- su carácter de proceso heurístico frente a los procedimientos deterministas,

Scire. 2 : 1 (en.-jun. 1996). 
- el lugar de clasificación en el proceso de comunicación documental, y

- los elementos y factores presentes en el contexto de la operación de clasificar que la condicionan.

En otros dos trabajos paralelos a éste — que se publicarán en un manual coordinado por María Pinto (García Marco, en prensa) — abordamos los objetivos y fases de la operación de clasificar, así como su lógica desde el punto de vista del objetivo fundamental de cualquier sistema documental: la recuperación.

Nuestra perspectiva va a ser, desde un punto de vista teórico general, el análisis de sistemas; desde un punto de vista de gestión vamos a adoptar el enfoque denominado de 'calidad total'.

El enfoque sistémico intenta siempre realizar un análisis funcional de cualquier problema, enmarcándolo en su contexto y desentrañando la función -o disfunción - adaptativa que realiza en el sistema al que pertenece. El análisis de sistemas los conceptualiza como conjuntos de elementos en interacción dinámica en función de un objetivo. Exige determinar el conjunto de elementos que lo forman, los elementos relevantes de su entorno, los procesos y las relaciones que los ligan a todos ellos, asi como el objetivo u objetivos globales del sistema aquellos que le proporcionan su unidad-y su evolución.

El enfoque de 'calidad total' (CT) pretende asegurar que los sistemas se comportan con eficacia - cumpliendo con los objetivos externos que los hacen relevantes - y eficiencia - funcionando internamente de forma económica y productiva- - La CT exige que cualquier proceso productivo o cualquier servicio esté orientado a las necesidades de los consumidores o usuarios que lo hacen funcional, que se convierten en la norma contra la que evaluar el funcionamiento del sistema, y supone un control real y cuantitativo respecto a dicho estándar tanto de los productos como de los procesos que los originan.

Vamos a continuación a tratar el primer problema que nos planteábamos: el carácter heurístico de la metodología de la clasificación.

\section{3.¿Qué es un proceso?}

Tanto las metodologías como las operaciones son tipos especiales de procesos. Podemos definir un proceso como una estructura que detectamos en la línea del tiempo, frente a los objetos, que son estructuras percibidas en el espacio. En general, llamamos proceso a cualquier fenómeno activo, dinámico y cambiante, que, a diferencia de los acontecimientos o eventos, que son únicos e irrepetibles por definición — como Mayo del 68 o la Guerra de Cuba—, sea recurrente —ocurra una y otra vez-, y esté estructurado de forma secuencial, es decir, que sea divisible en fases más pequeñas. El acontecimiento es coyuntural, el proceso tiene carácter estructural.

Scire. 2 : 1 (en.-jun. 1996). 


\section{4.¿Qué es una operación?}

Una operación es una acción o intervención que conduce desde un estado inicial a un estado final pre-determinado, o, dicho de otro modo, que produce una transformación. Así, por ejemplo, una operación quirúrgica persigue devolver un organismo dañado a un estado más saludable. Decimos que el estado final de una operación está predeterminado porque cualquier operación supone alcanzar unos objetivos, que han sido fijados con mayor o menor claridad de antemano. Con su acostumbrada precisión terminológica, los matemáticos denominan operación a una función que conduce desde un conjunto inicial a un conjunto final. En la vida real, frecuentemente, no basta con una sóla operación para conseguir el resultado deseado, sino, más bien, una secuencia de operaciones desarrolladas en un orden dado, lo que los matemáticos denominan algoritmos. Desde este punto de vista, podemos considerar la operación como la unidad analítica intermedia entre la variable aislada y el algoritmo completo.

En las ciencias aplicadas, una operación es una intervención que — a partir de una serie de materiales, pre-condiciones y un cierto gasto de energía- nos permite conseguir un producto dado. En nuestra ciencia, la Documentación —una ciencia aplicada, como sabemos-, la palabra operación suele tener este sentido. Precisamente la 'cadena documental' —el proceso o 'camino' que los documentos sufren dentro de una unidad de información- se define como el conjunto de operaciones que se realizan sobre los documentos para organizarlos de manera que sea posible su recuperación en respuesta a determinadas demandas de los usuarios. La expresión 'cadena documental' responde a una conceptualización metafórica, realizada por analogía con las cadenas de montaje industriales, donde el producto va sufriendo una serie de operaciones perfectamente predefinidas en su calidad, cantidad y secuencia hasta quedar listo para el consumo.

La profesora María Pinto (1991, p. 76) nos ha ofrecido un excelente modelo del tratamiento documental como secuencia de operaciones. En su modelo, la cadena documental aparece como un conjunto de procesos que generan unos productos específicos, y que se agrupan en dos grandes fases —el análisis formal y el análisis de contenido-, que, junto a una capacidad analítica y sintética común, requieren habilidades y conocimientos claramente diferentes.

A diferencia de la fábrica, la unidad de información es, en esencia, una unidad de servicios, no de producción. En este sentido, se parece mucho más a una gran unidad comercial de venta directa bien organizada, como los supermercados. Para desarrollar su actividad, el supermercado elabora representaciones de los aspectos relevantes de la realidad, y mantiene sus catálogos de proveedores, productos y clientes. El personal del supermercado dispone también la oferta de productos en estantes de 'libre acceso' organizándolos por materias y clasificán-

Scire. $2: 1$ (en.-jun. 1996). 
dolos con sumo cuidado. También necesitan de un depósito o almacén, del cual van sacando los productos según se va requiendo. La biblioteca de acceso público es — salvando las distancias — una especie de supermercado de libros, y como tal supermercado requiere también una cuidadosa ordenación y mantenimiento de los productos que ofrece en los estantes de cara a su 'recuperación'.

Sin embargo, y a pesar de ser fundamentalmente entidades del sector servicios, las unidades de infomación sí que elaboran un producto específico necesario para cumplir adecuadamente con el servicio que pretenden ofrecer. Ese producto es la base de datos o catálogo de referencias, y, ciertamente, su producción sigue las mismas leyes generales que la producción industrial.

\section{5.¿Qué significa 'metodología'?}

La metodología puede ser definida, por su parte, y en atención a su etimología griega, como la 'ciencia del camino'. También podríamos denominarla 'ciencia del proceso', entendida aquí la palabra proceso en su sentido originario de 'acción de caminar', y cuyo significado originario se conserva en castellano, por ejemplo, en la palabra 'procesión'. Este sentido de la palabra metodología conecta analógicamente con el significado de operación, pues en ambos casos se refieren a tipos especiales de comportamientos físicos o mentales que conducen paso a paso a una meta o fin pre-determinado. Resaltamos en cursiva la expresión 'paso a paso' para destacar el aspecto analítico de la reflexión metodológica, cuyo objetivo es precisamente ese, llegar a una meta definiendo claramente los pasos a dar.

Esta definición nos recuerda el viejo chiste de aquel caminante que se maravillaba de que 'andar fuera dar un paso detrás de otro'. Sin embargo, sonrisas aparte, cualquier persona que ha practicado el caminar o trepar por lugares difíciles sabe que, precisamente, el alcanzar cualquier meta, por difícil que sea, es simplemente cuestión de elegirla, seleccionar el mejor de los caminos posibles hasta ella, y estudiar con cuidado, de uno en uno, cada paso que hemos determinado dar.

De forma más neutra en nuestro idioma, podríamos también definir la metodología como la 'ciencia del procedimiento', palabra esta última que conserva el sentido etimológico del paso a paso, pero superando, no sé si para bien o para mal entender, la metáfora del caminante, esencial como hemos visto en la connotación del concepto de 'metodología'. Efectivamente, en español, método y procedimiento son sinónimos, y se pueden utilizar indistintamente en el registro culto no especializado.

La 'metodología' sería, en definitiva, la ciencia del ‘cómo' conocer mejor la realidad y 'cómo' operar con más eficacia sobre ella; del 'recto proceder', en 


\section{6}

definitiva. En concreto, esta ciencia nos ayudaría a decidir o determinar qué tipo de operaciones debemos realizar para conseguir un fin determinado, cómo seleccionarlas y prepararlas, así como el orden en que deberíamos ejecutarlas. Como sabemos, la metodología no existe como ciencia independiente, sino que se desarrolla como un aspecto más dentro del problema general del conocimiento humano - estudiado por la Epistemología y las Ciencias Cognitivas (1) - y, específicamente, dentro de cada ciencia y aspecto del saber como un campo de investigación ineludible, pero fundamentalmente aplicado. En este último sentido hablamos de una metodología o de metodologías. A saber, aquí no utilizamos 'metodología' en el sentido de ciencia del correcto proceder, sino como procedimiento específico que nos ayuda a alcanzar un fin también específico. Quizá en este caso sería más propio hablar de método o procedimiento, y el uso en este contexto de la palabra metodología responda más bien la deseo de beneficiarnos del prestigio del sufijo -logia (ciencia) en nuestra actividad diaria.

Existen dos grandes tipos de métodos: los deterministas — denominados, como hemos visto, algoritmos - y los no deterministas —o heurísticos-. Los métodos de tipo determinista se pueden descomponer en una serie de pasos previamente detallados y cuantificados que conducen irrevocablemente a un resultado inequívocamente definido. Esto es posible porque, en los procesos deterministas, las variables que determinan los resultados han sido fijadas inequívocamente, y sus valores medidos con precisión. Evidentemente, los métodos deterministas exigen y permiten el control riguroso del ambiente o contexto. El ejemplo típico de proceso determinista es un programa de ordenador. Por el contrario, en las operaciones no deterministas no es posible fijar con absoluta precisión ni el objetivo, ni el punto de partida, ni la secuencia de las tareas a realizar. Un ejemplo cotidiano de proceso heurístico puede ser hacer una buena paella. Si la clasificación fuera un proceso algorítmico sería posible determinar una operación por la que a cualquier documento le correspondiera necesariamente un número de clasificación y sólo uno.

Los filósofos de la ciencia y muchos científicos y humanistas han discutido con pasión si la realidad está determinada en sí misma (o no), y si el hecho de que un proceso dado nos aparezca como algorítmico (o no) es consecuencia del grado y tipo de conocimiento que tenemos de ellos. Recientemente, un experto mundialmente conocido en el campo de la clasificación, Robert Fugmann, argumentaba que el proceso de indizar - incluyendo claro está el de clasificar- es inherentemente no determinista (Fugmann, 1994). En cualquier caso, hoy por hoy no hemos sido capaces de operacionalizar ni nuestros objetivos ni nuestros procedimientos hasta convertir la clasificación en una 'ciencia exacta'. Por otra parte, esta es una situación que compartimos con el resto de las ciencias sociales y humanas, de las cuales incluso las más normativas — como el Derecho- dis-

Scire. 2 : 1 (en.-jun. 1996). 
tan mucho de plantear fines y procedimientos completamente objetivos y precisos.

Eso no quiere decir, sin embargo, que no se hayan precisado esos objetivos y secuencias en un grado considerable en el siglo ya largo que llevamos desarrollando clasificaciones universales, desde que en 1876 Melvil Dewey publicara su Clasificación Decimal.

Un aspecto ineludible de toda reflexión metodológica es decidir si deseamos hacer metodología científica. La metodología científica experimental exige la creación de modelos representativos del dominio que estudiamos de tal forma que sean contrastables - falsables, diría el desaparecido filósofo Karl Poppercon la realidad. Esta claro que, en nuestro campo, todavía no hemos llegado a la fase experimental. Nuestros modelos son descriptivos de prácticas tradicionales y, en menor medida, exploraciones teóricas de carácter integrador.

De todo lo anterior se concluye lo siguiente:

a) que para comprender cualquier operación es necesario comprender claramente sus fines u objetivos.

b) que, en el caso de la clasificación documental, se trata de objetivos formulados a nivel general e intermedio, sin la suficiente especificidad y exactitud para resultar en una operacionalización determinista del proceso de clasificar. Por tanto, la clasificación documental es un proceso no determinista, que, al menos por ahora, no se ha expresado por medio de algoritmos.

c) que, sin embargo, existen una serie de procedimientos establecidos, consejos generalmente aceptados y una secuenciación de sub-objetivos que forman un esquema heurístico propio que debe tenerse en cuenta por cualquier clasificador. Es decir, la ausencia de una determinación estricta de objetivos no excluye la especificación de sub-metas suceptibles de guiar nuestro trabajo.

d) que debemos esforzarnos en caminar hacia una auténtica metodología científica en nuestra práctica investigadora y profesional. Y ello pasa por la construcción de modelos y su contrastación con la realidad.

En definitiva, plantearnos el problema de la clasificación documental como operación supone preguntarnos de forma general qué criterios utilizar para que, partiendo de un producto concreto —el documento-, obtengamos otro - el documento secundario - con el objetivo de facilitar la recuperación y la gestión del primero. Ya en particular, supone precisar sus objetivos distintivos frente a las demás operaciones documentales, las principales variables que intervienen en ella, sus aspectos determinantes y sus fases de ejecución. Este es el esquema de reflexión que vamos a seguir en las páginas siguientes y en los trabajos paralelos que hemos realizado sobre la metodología de la clasificación (García Marco, en

Scire. 2 : 1 (en.-jun. 1996). 
prensa).

\section{La clasificación en el sistema de representación y recuperación de la información}

\subsection{Realidad, conocimiento y documento}

La Documentación es una ciencia eminentemente orientada a fines de orden práctico. Para ello investiga y sistematiza saberes teóricos que luego sirven para mejorar la práctica de los profesionales de la información documental. Es decir, desarrolla un saber aplicable y aplicado, gobernado por la ética científica y profesional. En concreto, todos sus esfuerzos buscan optimizar la circulación de la información documental en la sociedad para ayudar al progreso y a la felicidad de los seres humanos que la forman.

Efectivamente, nuestra experiencia cotidiana nos muestra como la sociedad depende de la información escrita y audiovisual — fijada en documentos- para su funcionamiento. ¿Por qué es tan necesaria la información documental? Sencillamente porque nos ayuda a conservar de forma más duradera, estable, replicable y manejable los conocimientos e imágenes que necesitamos para representarnos la realidad, y que nos permiten desempeñarnos correctamente en ella. Todos somos conscientes de que nuestra memoria — donde guardamos imágenes y conocimientos - es muy limitada, y sujeta al olvido. Afortunadamente, ya desde niños aprendemos también cómo fijar esos conocimientos. Sabemos que por medio de la escritura y de las grabadoras de sonido e imagen podemos almacenarlos fuera de nosotros en esas memorias externas que son los documentos.

Ahora bien, ya dice el adagio que "toda solución engendra nuevos problemas": la propia durabilidad de los documentos y el interés de la información que contienen nos lleva a almacenarlos, y a permitir su continua acumulación. Desde la aparición de la imprenta y todavía más desde el surgimiento de las tecnologías de la información y la documentación, el crecimiento exponencial de la masa de documentos plantea enormes problemas de circulación y acceso a la información que contienen. Como ha señalado Karl Popper, en su celebre teoría de los tres mundos, el entorno del hombre no es tan sólo — como ingenuamente podríamos creer - la realidad circundante (mundo 1), sino también los conocimientos que utilizamos para desenvolvernos eficazmente en ella (mundo 2), y el universo de documentos en el que hemos ido almacenando esos conocimientos (mundo 3) (Fig. 1). Dicho de otro modo, nuestra vida como seres sociales se desarrolla en tres entornos indisolublemente imbricados que se influyen mutuamente: el mundo físico, el cultural y el documental.

Se trata de mundos que son todo menos estáticos, son mundos en continua

Scire. 2 : 1 (en.-jun. 1996). 
transformación e información. Cada uno de ellos está sujeto a sus propias leyes, pero la relación entre ellos es estrecha y está controlada por los principios de relevancia, representación y correspondencia funcional. El principio de relevancia afirma que sólo atendemos a aquellos aspectos de la realidad que nos afectan o pueden ser útiles a nuestros objetivos, determinados en gran parte por nuestras necesidades. El principio de representación implica que el mundo cognitivo tiende a representar fielmente y con la exactitud necesaria dichos objetivos al mundo físico, y, consiguientemente, que el documental debe representar fielmente el mundo cognitivo. El principio de correspondencia funcional postula que el funcionamiento del mundo cognitivo intenta reproducir el funcionamiento del mundo físico de tal manera que permita el cálculo mental y la predicción, y paralelamente, que el mundo documental tiende a funcionar y estructurarse como el cognitivo en lo que corresponde a dichas necesidades.

\subsection{El mundo documental}

En definitiva, los documentos no son un mundo independiente y con sentido pleno, sino que el mundo documental depende del sistema socio-cultural que lo utiliza y mantiene, y reproduce su estructura. El sistema documental de una sociedad es su memoria secundaria, de donde ésta recupera continuamente informaciones y conocimientos importantes que, de otra manera, tendría que reinventar o transmitir con gran costo social por via oral.

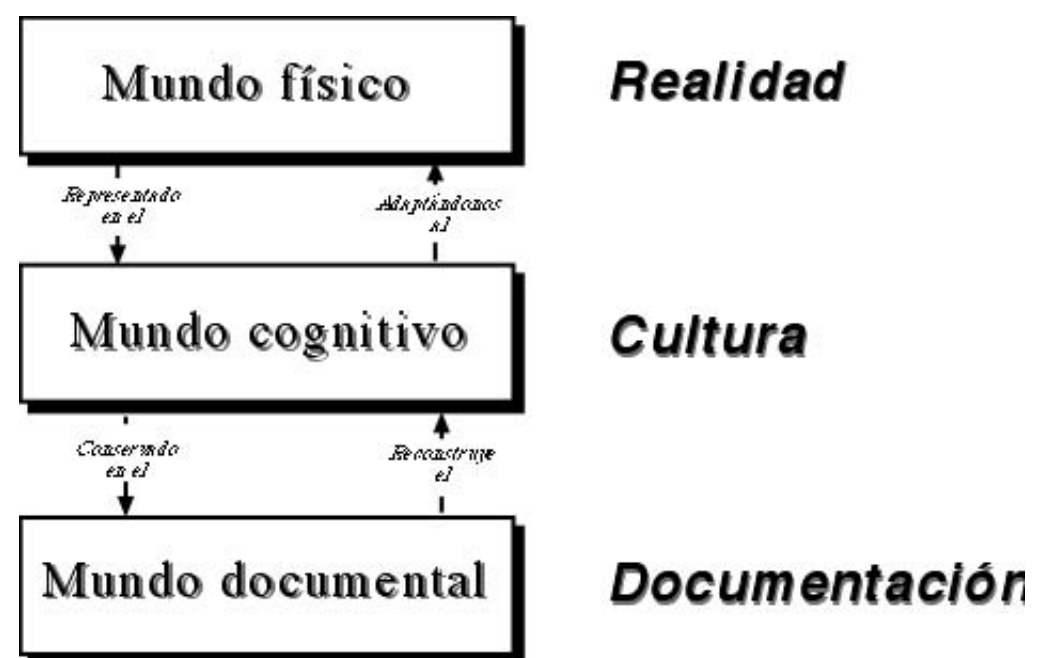

Fig. 1. Los tres mundos de Karl Popper (recreación)

Scire. $2: 1$ (en.-jun. 1996). 
Así pues, cualquier documento es parte de un sistema documental, y éste a su vez es un fiel reflejo del sistema socio-cultural, que ha producido y/o consume esos documentos. Los de carácter político-administrativo y jurídico reproducen - y revelan, como bien saben el historiador, el archivero y el sociólogo- la estructura del sistema institucional de la sociedad. Los documentos científicos, por su parte, se estructuran a lo largo y ancho del sistema social de conocimiento, estructurado institucionalmente en redes y centros de investigación y enseñanza, pero también de forma más laxa en asociaciones y grupos informales.

En resumidas cuentas, los documentos permiten almacenar y transmitir la información y conocimientos que los distintos sistemas y grupos sociales necesitan para funcionar adecuadamente. Dado el exponencial crecimiento y complejidad del sistema documental en nuestras sociedades, ha surgido en ellas una nueva división del trabajo fruto de la cual es el llamado sector cuaternario, dedicado a la gestión social de la información y de la documentación, del mismo modo que existe el sector primario — extractivo y agrícola-ganadero-, secundario o industrial, y terciario o de servicios.

El mundo documental, como el de la realidad y el del conocimiento, forma un sistema, esto es, un todo interrelacionado que es mucho más que la simple suma de sus partes. Los documentos no existen aisladamente unos de otros, sino que forman parte de un sistema universal de documentos. Este no es un postulado teórico, sino una constatación empírica. Que los documentos no pueden entenderse de forma individual puede comprobarse fácilmente buscando en un texto citas de otros textos —reconocidas o no-, así como las referencias implícitas y explícitas que contienen a otros documentos. Además, los textos se conforman según reglas pragmáticas, gramaticales y semánticas contenidas en otros documentos: los reglamentos y leyes, las gramáticas y los diccionarios. Este sistema conforma lo que tradicionalmente se ha denominado 'cultura escrita', que hoy en día, debemos extender a los documentos audiovisuales, sea cual sea su formato, $y$, que en un sentido amplio, abarca también a los monumentos, objetos artísticos cultura artística - y artefactos — cultura material—. En un sentido amplio, nuestra cultura constituye un gran "megadocumento", compuesto de textos clásicos - con sus epígonos, polemistas y periféricos-, sus comentarios, rutas de lectura, y centros donde dichos documentos se crean, almacenan y transmiten. El mundo de la cultura pública, ya sea humanística, científica o audiovisual es el campo para el que se han desarrollado las clasificaciones bibliográficas, en las que nosotros vamos a concentrar nuestro interés.

Sin embargo, el mundo documental no está limitado, ni mucho menos, al mundo de la cultura, sino que sirve también como control directo de la vida social, fijando en documentos las transacciones, obligaciones y constricciones a las que se someten —o son sometidas— las personas en su vida social: leyes,

Scire. $2: 1$ (en.-jun. 1996). 
contratos, acuerdos, mensajes, etc. Este campo es el objeto específico de una de las ciencias de la documentación: la Archivística, para la cual es fundamental también la clasificación como operación e instrumento, normalmente de tipo enumerativo. También son necesarias las clasificaciones en el mundo de los objetos y bienes inmuebles portadores de valor cultural y científico —en definitiva de interés informativo- , ya dentro de los dominios de la gestión del patrimonio cultural y de la Museística.

\subsection{El sistema social de comunicación documental}

Además de la estructuración sociológica y temática del conocimiento que hemos estudiado en el apartado anterior, el sistema documental está dotado de una vertiente dinámica que lo convierte en un sistema de comunicación. Este sistema de comunicación social del mundo documental está fuertemente estructura-

\begin{tabular}{|c|c|c|}
\hline Funciones documentales & $\begin{array}{l}\text { Actividades } \\
\text { documentales }\end{array}$ & $\begin{array}{l}\text { Subsistemas de información } \\
\text { documental }\end{array}$ \\
\hline Creación & Creación & $\begin{array}{l}\text { Universidades } \\
\text { Centros de investigación } \\
\text { Individuos } \\
\text { Sociedades, etc. }\end{array}$ \\
\hline \multirow[t]{3}{*}{ Producción y publicación } & Producción & $\begin{array}{l}\text { Imprentas } \\
\text { Estudios } \\
\text { Productores de bases de datos, etc. }\end{array}$ \\
\hline & Publicación & $\begin{array}{l}\text { Editoriales } \\
\text { Medios de Comunicación de Masas } \\
\text { Mantenedores de bases de datos, etc. }\end{array}$ \\
\hline & $\begin{array}{l}\text { Divulgación y notificación } \\
\text { de apoyo(publicidad) }\end{array}$ & $\begin{array}{l}\text { Empresas y agencias de publicidad } \\
\text { Medios de comunicación } \\
\text { Enseñanza, etc. }\end{array}$ \\
\hline \multirow[t]{3}{*}{ Distribución } & $\begin{array}{l}\text { Distribución (mayoristas de } \\
\text { referencias y doc.primarios) }\end{array}$ & $\begin{array}{l}\text { Dsitribuidores editoriales } \\
\text { Distribuidores audiovisuales } \\
\text { Distibuidores de bases de datos } \\
\text { Grandes bibliotecas } \\
\text { Redes de bibliotecas, etc. } \\
\end{array}$ \\
\hline & Transporte físico & $\begin{array}{l}\text { Correos, operadoras de } \\
\text { telecomunicaciones } \\
\text { Mensajería } \\
\text { Redes de televisión, etc. } \\
\end{array}$ \\
\hline & $\begin{array}{l}\text { Distribución local } \\
\text { (minoristas de doc. primaria } \\
\text { ysecundaria) }\end{array}$ & $\begin{array}{l}\text { Pequeñas y medianas Bibliotecas } \\
\text { Centros de documentación } \\
\text { Librerías, etc. }\end{array}$ \\
\hline \multirow[t]{2}{*}{ Utilización } & Gestión de redes de uso & Centros coordinadores, etc. \\
\hline & $\begin{array}{l}\text { Gestión del uso local } \\
\text { (minoristas) }\end{array}$ & $\begin{array}{l}\text { Pequeñas y medianas Bibliotecas } \\
\text { Archivos } \\
\text { Museos, etc. }\end{array}$ \\
\hline
\end{tabular}

Fig. 2. División del trabajo en la circulación documental

Scire. $2: 1$ (en.-jun. 1996). 
do, y es enormemente dinámico. No es extraño, por supuesto, que la sociedad se organice a sí misma para gestionar más eficazmente el mundo del conocimiento y de los documentos que lo almacenan. Igual que ocurre en la producción de alimentos o de máquinas industriales, existe en nuestra sociedad una división del trabajo que da cuenta de todo el proceso de circulación de los documentos desde su creación, producción y publicación hasta su distribución al usuario final y utilización por éste. La perspectiva dinámica del mundo documental nos muestra las grandes clases de operaciones realizadas para crear y transmitir los documentos - y que se corresponden con las funciones que desempeña para el sistema social—: creación, gestión, distribución primaria — de documentos originales y copias literales-y distribución secundaria — de referencias (documentos secundarios) y colecciones de referencias (documentos terciarios)—. Dependiendo de la escala a la que operen las células del subsistema documental estarán más o menos especializadas en alguna de estas grandes funciones. Así, por ejemplo, una pequeña institución puede integrar todas las funciones en una única unidad de documentación que se ocupe desde generar los manuales de la institución a mantener la colección de libros o hacer difusión de los artículos de la colección de revistas, mientras que la economía de escala permite la existencia de industrias de producción editorial o de distribución secundaria. Podemos verlo de forma más detallada en el siguiente cuadro (Fig. 2):

Estos procesos de división social del trabajo han surgido de forma independiente al desarrollo de la ciencia documentológica con fines absolutamente prácticos y empíricos. Sin embargo, la Documentación como ciencia intenta comprender el fenómeno de la circulación documental, y desde este conocimiento científico, busca modelizarlo, intervenir —operar- en él y optimizarlo. Su objetivo, en definitiva, es comprender y optimizar la transferencia documental de los conocimientos y de los datos que necesitamos para generarlos y actualizarlos.

\subsection{El servicio de información documental}

Ahora bien, ¿cómo realiza el documentalista su función? El documentalista organiza el mundo de la información documental tomando los documentos como materia prima y ofreciendo a partir de ellos una serie de productos y servicios que facilitan al resto de la comunidad el acceso a ella. El servicio documental —difícilmente hoy en día ningún servicio de información puede funcionar sin documentos - se enquista entre la oferta y la demanda de documentos, mediando entre ambas partes, y facilitando su encuentro a través de dichos productos y servicios. En la consecución de ese objetivo mediador y optimizador de la circulación de la información documental, el servicio documental realiza numerosas operaciones. El quicio de esas operaciones es la elaboración —durante la fase de entrada y de tratamiento- de unas representaciones de los documentos suficien-

Scire. $2: 1$ (en.-jun. 1996). 
tes para individualizarlos, discriminarlos, recuperarlos y gestionarlos según las necesidades de los usuarios del servicio. Esas representaciones — denominadas documentos secundarios — rigen después la ordenación, almacenamiento y recuperación de los documentos primarios.

En último término, y por tomar una metáfora conocida por cualquiera de nosotros, el servicio documental funciona de forma semejante a cualquier comercio. Así por ejemplo, una tienda que vende electrodomésticos media entre la oferta producida en las fábricas y los clientes que esperan alcanzar una vida más cómoda adquiriéndolos. Para ello, el vendedor o grupo de vendedores exploran el mercado y reciben a los representantes de los industriales productores formándose una idea clara del mayor número posible de productos disponibles. A partir de ese conocimiento del mercado, van elaborando un catálogo con el nombre de cada electrodoméstico, precio, lugar donde adquirirlo, condiciones de pago, ven-

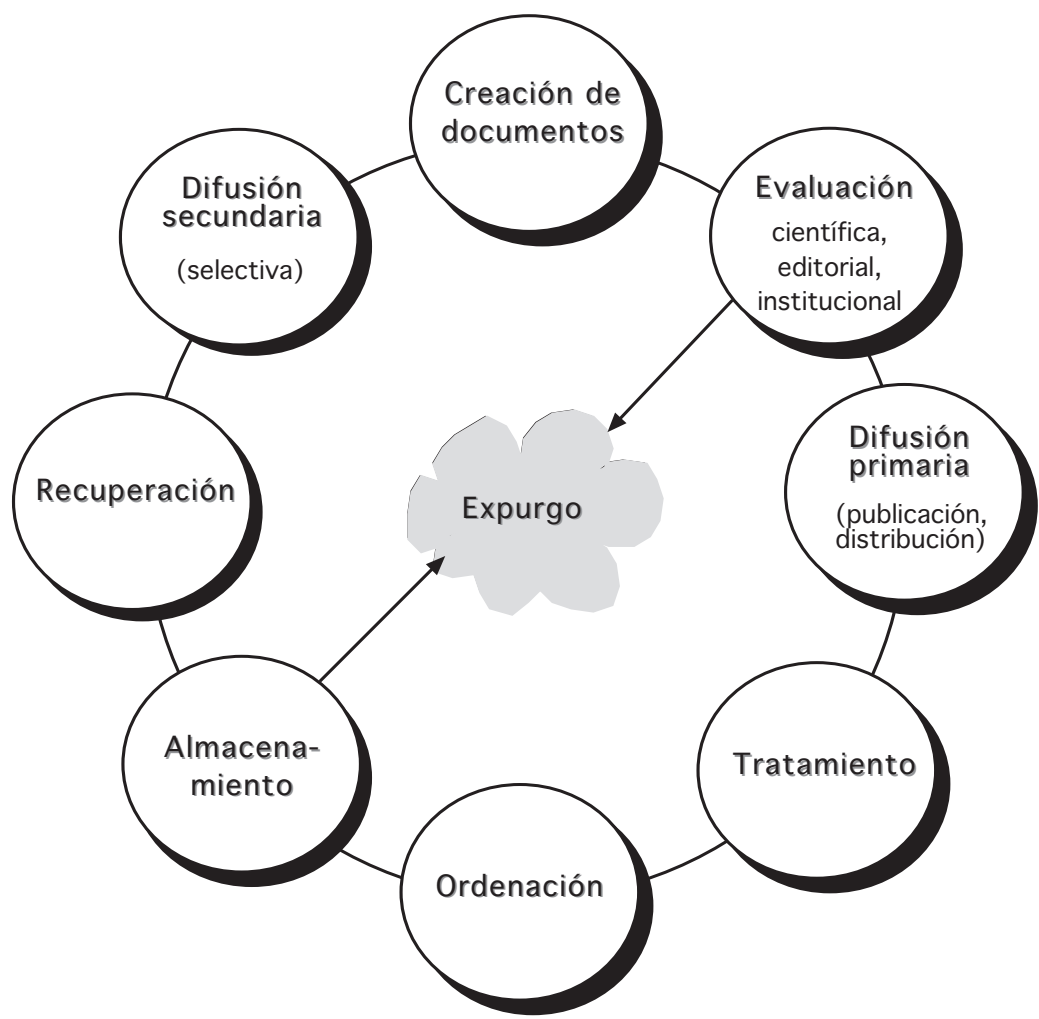

Fig. 1. El ciclo del documento

Scire. $2: 1$ (en.-jun. 1996). 
tajas y desventajas en comparación con otros productos similares, y toda la información necesaria. Paralelamente, el buen vendedor estudia a sus clientes y se percata de sus características y necesidades diversas, comprendiendo que cada producto tiene su cliente y cada cliente su producto. Esa idea más o menos clara del mundo de los productores, los productos y los clientes que el vendedor de electrodomésticos necesita para desempeñar su trabajo correctamente es lo que llamamos sus conocimientos.

\subsection{La documentación como proceso de comunicación}

En definitiva, el proceso documental es un proceso de mediación comuniacional en el cual el canal es un soporte permanente, ya sea en el espacio o en el tiempo (López Yepes, 1981, 1994). En cuanto que proceso de comunicación, no es sino una concrección del modelo clásico de comunicación (MCC) postulado por Shannon y Weaver, y en el que se describen los elementos y procesos ideales de todo sistema de comunicación (Fig. 4).

Dicho modelo es un referente imprescindible en todas las ciencias humanas y sociales, no sólo en la ingeniería de telecomunicaciones, en cuyo seno surgió. Ello no es extraño, pues se trata de un modelo extraordinariamente fructífero, pues tiene la virtud de aislar los elementos y procesos de los que depende el éxito de una comunicación, que se sintetiza en dos tipos de flujos. En primer lugar, la señal emitida por el emisor debe alcanzar al receptor, superando las dificultades que suponen las fuentes de ruido y los procesos entrópicos — de pérdida de energía e información— que le afectan. En segundo lugar, el mensaje ha debido

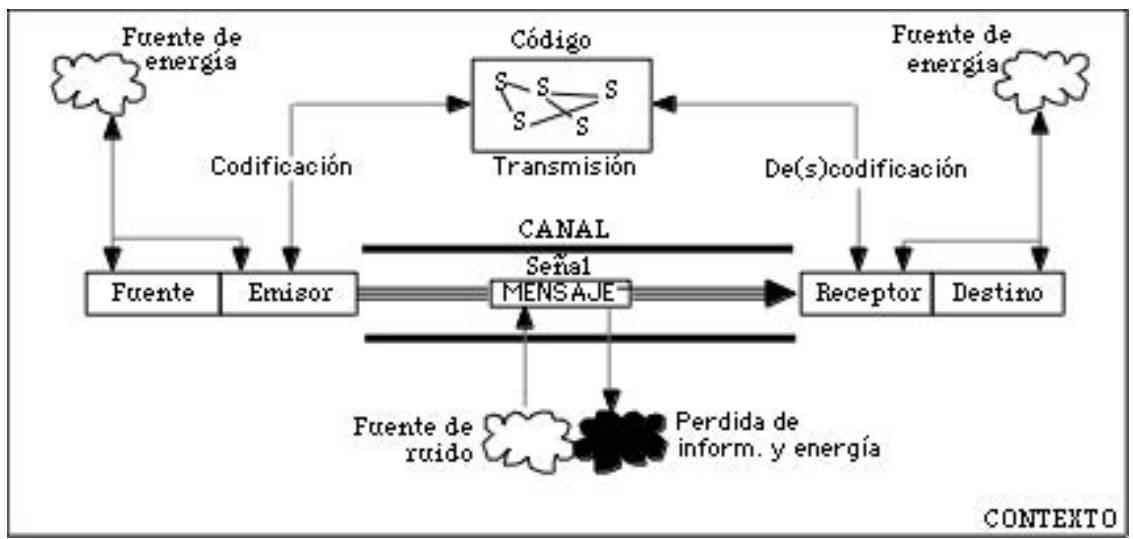

Fig. 4. El modelo clásico de comunicación (MCC)

Scire. 2 : 1 (en.-jun. 1996). 
codificarse en forma de señal tomando como referencia un código común a emisor y receptor, lo cual supone afirmar que toda comunicación necesita de un lenguaje o semiosistema. Al lector no se le escapa que el MCC es una simplificación, que está orientada a iluminar la unidad mínima de comunicación: los eslabones emisor-receptor (e-r). Cuando en un proceso de comunicación coinciden la fuente y el emisor, por una parte, y el receptor y el destino, por la otra, decimos que es un proceso de comunicación primario. Un caso de proceso de comunicación primario es, por ejemplo, la conversación entre personas.

Sin embargo, los procesos comunicacionales que estudiamos en el mundo documental suelen, por lo común - y con la excepción de los estudios de transacciones-, estar compuestos de varios eslabones (e-r). O, dicho de otro modo, la fuente y el destino están separados por numerosos eslabones (e-r), cuya función es eminentemente mediacional. Como veíamos en páginas anteriores, el proceso de comunicación documental es una actividad de mediación entre el productor o distribuidor de la información y el usuario final de esa información u otro distribuidor secundario. Es un proceso comunicacional, no meramente informativo, como se afirma a veces. Cuando hablamos de proceso de información, tomamos una perspectiva más psicológica, más centrada en los procesos que acontecen en los actores individuales de la comunicación, y menos en el sistema de comunicación (social) establecido. Efectivamente, la acción de informarse no exige necesariamente la comunicación: una persona puede informarse por simple observación. Sin embargo, en el proceso documental lo que acontece es una comunicación de información entre emisor y receptor, por más que sea mediata en el tiempo y en el espacio. Y, en cuanto que tal comunicación, se trata de un proceso de información de tipo simbólico y eminentemente interaccional.

En el gráfico siguiente (Fig. 5) desarrollamos un modelo del sistema de comunicación documental, a partir del modelo clásico de Shannon y Weaver. En él podemos contemplar el sistema de comunicación documental como un sistema compuesto de tres subsistemas: los productores — que constituyen la oferta de información—, los usuarios — que constituyen la demanda—, y los mediadores - los sistemas de información documental- Se trata de un modelo simplificado de una cadena que, como hemos visto en la figura 3, es mucho más compleja. Pero nos permite aislar los elementos y procesos fundamentales que acontecen en los sistemas de almacenamiento, conservación y recuperación de información (SACRIs).

El código por excelencia que rige el proceso de comunicación documental es el lenguaje natural. Sin embargo, la complejidad y riqueza de matices de las lenguas humanas y los límites estructurales y funcionales del SACRI — disponibilidad de horas/hombre en relación con los flujos de entrada y salida de documentos, ausencia de herramientas automáticas de procesamiento lingüístico,

Scire. 2 : 1 (en.-jun. 1996). 
etc.- hacen necesario limitarlo o sustituirlo por un código más restringido, preciso y controlado, al cual denominamos lenguaje de recuperación. El lenguaje de recuperación por excelencia es el conjunto de términos con el que se han descrito los documentos y que, por tanto, son aquellos por los que se puede buscar. Los sistemas automatizados suelen proporcionar además un lenguaje de interrogación, que consiste en una serie de operadores sintácticos para combinar los términos del lenguaje documental. Podríamos sintetizar afirmando que el lenguaje documental es el léxico del código documental, y que el lenguaje de recuperación es su sintaxis. No obstante, existen sistemas denominados en texto libre o len-

\section{Demanda}

CONTEXTO

Oferta

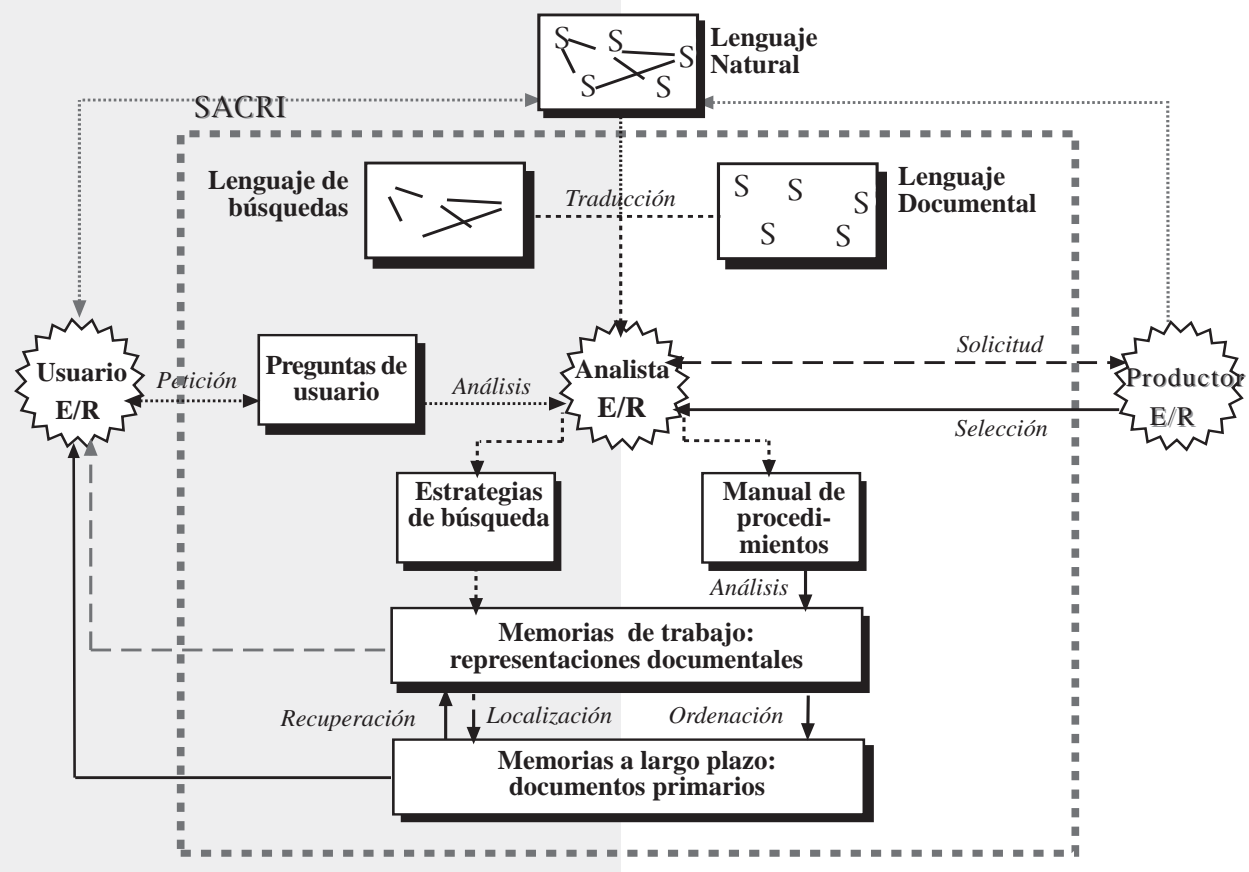

Elementos:

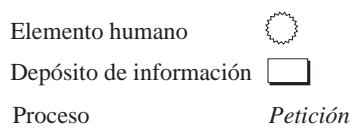

Flujos:

Documentos
Referencias
Uso del LN
Uso del LD y LR

Fig. 5. El proceso de comunicación desde el MCC

Scire. 2 : 1 (en.-jun. 1996). 
guaje natural que no utilizan lenguajes documentales con los consiguientes problemas de precisión y exhaustividad (2). Por supuesto, el ámbito del lenguaje de recuperación se reduce exclusivamente a la unidad de información, y el usuario puede verse expuesto a él, como en las bibliotecas; o no, como ocurre en la mayor parte de los servicios de información o documentación. Los mensajes que se intercambian en el SACRI son prioritariamente documentos o referencias acerca de ellos - que permiten localizarlos o decidir acerca de su relevancia a una determinada necesidad de información- y secundariamente otros datos de carácter instrumental y administrativo. El SACRI recibe, por un lado, noticias sobre la existencia de documentos interesantes a su población de usuarios; y, por el otro, peticiones de éstos. En el caso ideal, la retroalimentación entre oferta y demanda determina la política de adquisiciones de documentos primarios y de referencias del SACRI.

\subsection{La determinación de la comunicación documental por el sistema de representación}

Una vez que un documento - o su noticia — entra en el sistema, se realiza su representación bibliográfica y de contenido, y se almacenan ambos — documento y referencia - de forma ordenada en la base de datos de representaciones y en la base de datos primaria o almacén de documentos. Ante una consulta de un usuario (Fig. 6), el documentalista traduce su pregunta al lenguaje documental, interroga su base de datos de representaciones y le proporciona las referencias (representaciones) pertinentes. En muchos sistemas es el usuario el que busca directamente en el fichero de representaciones. Puesto que la base de representaciones es el lugar en el que se realiza la recuperación documental se le puede considerar la auténtica memoria de trabajo del SACRI. Si el usuario está interesado en algún documento, se recupera éste del almacén de documentos primarios (o se solicita al productor o a un intermediario si el SACRI sólo posee las referencias), utilizándose para ello la representación o referencia a modo de señal (signatura), pues ésta porta el lugar de almacenamiento de cada documento. Para ello debe ser capaz de formular verbalmente su necesidad de información, y él mismo —o el analista en su lugar - tiene que traducir su petición al lenguaje de recuperación — términos y sintáxis - y plasmarla en una estrategia de búsqueda comprensible por el SACRI.

Idealmente, el usuario debería recibir todos los documentos que el SACRI contiene capaces de satisfacer su necesidad de información. En la práctica, y como podemos ver en el gráfico anterior, eso raramente ocurre. Muchos documentos que podrían satisfacer al usuario no son recuperados (silencio) y un número importante de los documentos recuperados no responden a la necesidad 


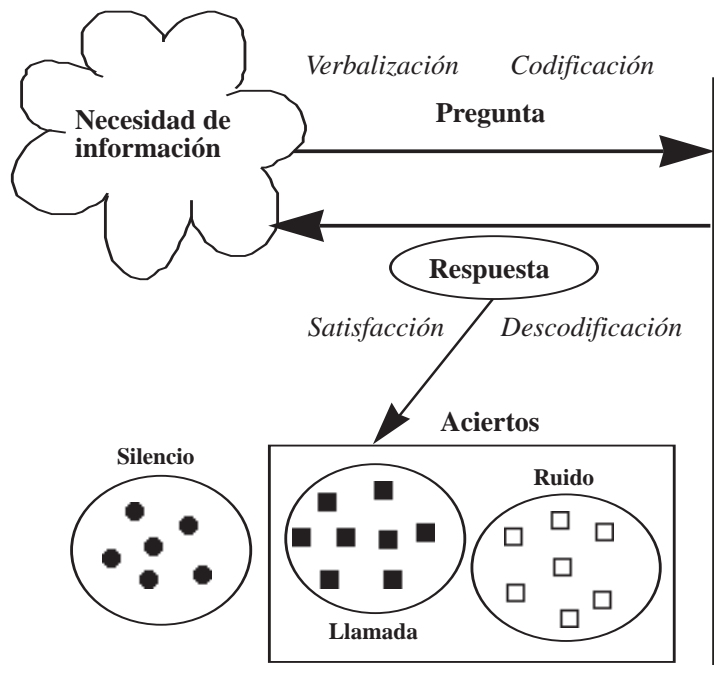

- Documentos relevantes a la necesidad de información no codificados por la pregunta y no recuperados (silencio)

- Documentos no relevantes no recuperados
Conjunto documental

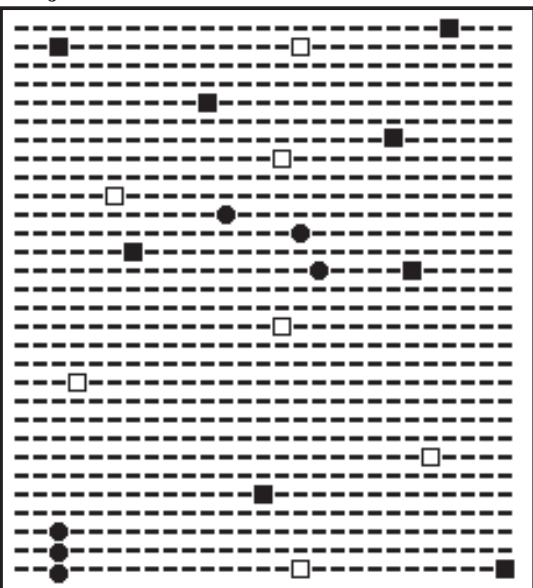

- Documentos relevantes a la necesidad de información codificados por la pregunta y recuperados

$\square \quad$ Documentos no relevantes a la necesidad de información codificados por la pregunta y recuperados (ruido)

Fig. 6. El diálogo documental

del usuario (ruido). Esto no ocurre por ninguna razón misteriosa, sino porque la codificación de la pregunta o de la indización ha sido deficiente por ambigua o incompleta. Es decir, por problemas de representación de la petición o de los documentos-respuesta en los lenguajes de indización y búsqueda. En definitiva, el problema básico de cualquier sistema documental es asegurar que la fracción de documentos que se sugieren al usuario después de una petición de referencias incluya el mayor número posible de los documentos relevantes contenidos o referidos en el sistema (exhaustividad), y el menor posible de los no relevantes (especifidad). Este es el quicio de la teoría de la representación y recuperación documental.

Para que el fichero de representaciones documentales sea recuperable, el usuario debe ser capaz de predecir el posible lugar de los documentos que necesita. Es decir, la organización de las bases de representaciones - $-\mathrm{y}$, por tanto, del propio SACRI — debe estar sintetizada en unos pocos principios fácilmente comprensibles por los usuarios y el personal especializado. En los últimos cincuenta años, los SACRIs han organizado su información según dos alternativas.

La primera es generar índices donde los términos del lenguaje documental se

Scire. 2 : 1 (en.-jun. 1996). 
ordenan bien alfabéticamente o bien según un orden conceptual, denominado sistemático. Esta estrategia es semejante a la que se sigue para facilitar la consulta de cualquier libro bien editado: el índice analítico ordenado alfabéticamente y el índice o tabla de contenidos que sigue un orden sistemático. Se trata de una hábil estratagema para proporcionar acceso a los documentos tanto desde el plano del significante - mediante el índice alfabético — como desde el del significado mediante el sistemático- - Según este sistema, la totalidad de los términos utilizados para describir un documento deben unirse en una sóla expresión que tenga un lugar inéquivoco y predecible dentro del índice. Por eso, se dice que los términos se hallan pre-coordinados, o que se trata de lenguajes documentales precoordinados. Son, en cualquier caso, lenguajes ordinales, es decir, orientados a crear secuencias ordenadas de términos, que unidos a la descripción bibliográfica y a los datos de localización y registro permiten mantener y recuperar los documentos y referencias almacenados en un SACRI. Así un libro sobre Historia de España en el siglo XIII podría recibir como materia España-Historia-Siglo XIII, y como número de la CDU 964.0"12”. Los lenguajes documentales precoordinados más importantes son los lenguajes de autoridades, los de materias y los de clasificación. Los dos primeros siguen un orden alfabético; y el último, conceptual. La precoordinación exige una sintaxis, es decir, unas reglas de combinación de los términos y unos signos que explicitan el tipo de relación que se da entre ellos.

La segunda alternativa surge con la aparición de sistemas automatizados de búsqueda combinatoria, especialmente con la aparición y desarrollo de los ordenadores, primero mecánicos y luego electrónicos. Los ordenadores son capaces de buscar con mucha rapidez cadenas de carácteres en sus memorias a largo plazo, tarea que se vuelve extraordinariamente rápida cuando se les añaden programas diseñados para mantener automáticamente índices ordenados de las palabras y expresiones guardadas en sus ficheros (índices inversos). Con ayuda de unos cuantos programas más, se puede dotar al sistema de un lenguaje de interrogación completo, con operadores lógicos, de comparación y proximidad, que permitan buscar combinadamente los términos y especificarlos. Los lenguajes de términos de búsqueda se denominan post-coordinados. En ellos, no es necesario formar una sóla cadena con todos los términos de indización, sino que los distintos términos describen al documento individualizadamente, y se denominan descriptores. Así el libro sobre Historia de España en el Siglo XIII al que nos referíamos antes podría describirse con los términos Historia Medieval, España, 1201-1300. Sin embargo, la precoordinación de los sistemas facetados o casifacetados tiene también ventajas en los sistemas automatizados: En particular, favorece la optimización del parámetro de especificidad, pues etiqueta el tipo de relación entre los términos de búsqueda, a diferencia de lo que hace el operador 
de intersección.

Para cumplir bien con su función el SACRI dispone como mínimo de cinco bases de datos interrelacionadas: el almacén de documentos primarios o reproducciones; el archivo de referencias documentales que sirve de representación condensada y de índice de los documentos primarios; el lenguaje documental, que sirve para conectar el vocabulario de las representaciones documentales y el de las estrategias de búsqueda; el fichero de preguntas de usuario, que sirve para determinar la política documental y evaluar el lenguaje documental respecto al vocabulario de uso; y el fichero de estrategias de búsqueda, que almacena traducciones de peticiones al lenguaje documental y de recuperación para su uso periódico para atender peticiones semejantes del mismo usuario o de nuevos usuarios, ahorrando tiempo y recursos. La mayor parte de los especialistas reconoce - aunque los designe con distintos nombres - estos tres bloques temáticos en el tratamiento documental: las operaciones de entrada o análisis (input), las operaciones de salida o recuperación (output), y las operaciones de control del código o lenguaje documental. En cualquier caso el tratamiento del documento determina la fase de recuperación, puesto que sólo se pueden buscar aquellos datos que han sido reflejados en la representación del documento.

\subsection{Las operaciones de representación documental}

Los procesos y técnicas de representación de los documentos y de las preguntas de los usuarios, así como el mantenimiento y optimización de los códigos documentales y todos los aspectos directamente relacionados con estas tareas han sido tradicionalmente denominados análisis documental, descripción documental o tratamiento documental. Las dos primeras expresiones son quizá léxicamente insuficientes, puesto que el análisis y la descripción son tan sólo fases del proceso de tratamiento documental; sin embargo, su uso está muy consolidado y debe mantenerse. Por supuesto, como el lector ya sabe, existe una diferenciación entre el análisis formal — cuyo objeto es la descripción bibliográfica- y el análisis de contenido — cuyo objeto es completar las notas de contenido que proporciona la descripción bibliográfica y proporcionar los puntos de acceso controlados correspondientes- L La distinción entre análisis formal y de contenido es congruente con la distintición clásica entre forma y sustancia. El análisis formal se nutre básicamente de la información proporcionada por la forma del documento - la portaday fuentes de información secundarias-, mientras que el análisis de contenido se centra en el contenido del documento, con el objeto de sintetizar su sustancia. Por otra parte, el análisis formal está ciertamente mucho más formalizado que el de contenido.

Sin embargo, la distinción entre análisis formal y de contenido no deja de plantear numerosos problemas. Así, por ejemplo, las áreas de la descripción

Scire. 2 : 1 (en.-jun. 1996). 
bibliográfica portan numerosa información sobre el contenido del documento, y de hecho esta información se aprovecha en los sistemas de recuperación en texto libre. Por otro lado, gran parte de la teoría de selección y control de puntos de acceso se viene incluyendo tradicionalmente dentro del análisis formal. Además, en muchas ocasiones, el propio análisis de contenido se efectúa mayormente sobre elementos que suspuestamente son formales, como el título. Por último, en los centros especializados y dotados de referencialistas o documentalistas, el análisis de contenido no se aplica tan sólo al documento, sino también a la petición del usuario con el objeto de generar una ecuación de búsqueda viable. Dados estos problemas terminológicos y conceptuales, nosotros preferimos denominar al proceso de crear representaciones de los documentos - lo que algunos autores anglosajones suelen denominar document surrogates - representación documental, o, simplemente, catalogación, término que se emplea tanto en bibliotecas como en archivos y museos.

A pesar de su interés teórico, estas discusiones no afectan a la práctica del tratamiento documental (3). Si en algo están de acuerdo la mayoría de los autores, es que el proceso de representación documental puede ser visto como una serie de operaciones que efectúan diferentes transformaciones sobre la representación documental hasta generar el registro bibliográfico (documental) completo. Cada una de ellas tiene una función específica, genera su propio producto, produce unos efectos distintivos en el SACRI y está regido por subcódigos y normas más o menos desarrollados. El tratamiento de este problema sobrepasa el marco de estas páginas, pero es condición ineludible de la correcta comprensión del proceso de clasificar. En el apartado y en el cuadro siguientes (Fig. 7, p. 128), el lector puede encontrar un resumen de las distintas operaciones y de sus respectivas funciones, productos, resultados y códigos normativos.

\subsection{Especifidad de la clasificación en la cadena documental: la indización sistemática}

Las tres operaciones documentales más importantes son la descripción, la indización y el resumen, subdividibles a su vez en una serie de operaciones más específicas. La función de la descripción bibliográfica es individualizar los documentos en cuanto que entidades bibliográficas y proporcionar sus datos identificativos básicos. La descripción de los ejemplares de las diferentes entidades bibliográficas posibilita su gestión y circulación controladas. La indización hace accesibles las descripciones bibliográficas - $-\mathrm{y}$ a través de ellas los documentos- a partir de la creación de un entorno de búsqueda predecible por el usuario, a saber, de índices. Dicha predicción es posible por la existencia de criterios de ordenación a priori que permiten otorgar uno o varios lugares inequívocos a la descripción bibliográfica en virtud de los distintos puntos de acceso que utiliza el

Scire. 2 : 1 (en.-jun. 1996). 


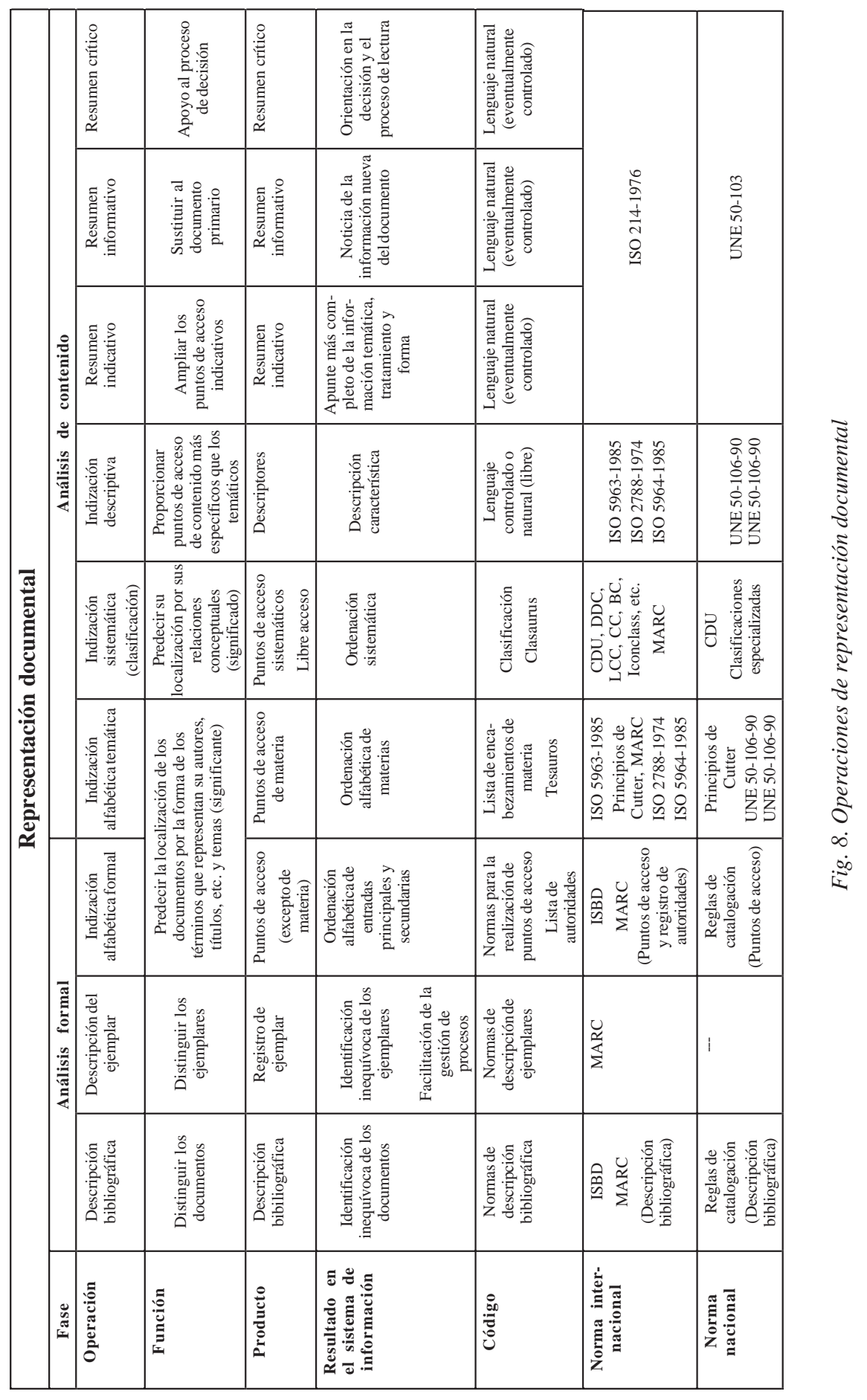


usuario: autores, títulos y materias. Los criterios de ordenación de las materias son, como hemos visto, de dos tipos: basados en el significante — según la secuencia alfabética — o en el significado — a partir de una organización conceptual-.

Una de esas operaciones de indización es precisamente la indización sistemática o clasificación. La indización sistemática, en cuanto que operación documental, y, por tanto, eminentemente comunicativa, requiere un código que posibilite el encuentro entre emisor y receptor. Las clasificaciones son lenguajes documentales — códigos — diseñados precisamente para servir a la indización sistemática: para hacer accesibles los documentos según una organización de carácter conceptual, que se suele denominar en nuestro campo organización del conocimiento. Se trata de situar cada documento en el lugar que ocupa dentro del sistema del saber en un orden prefijado y predecible. Para ello es necesario sistematizar primero dicho mundo del saber, de ahí que a la operación de clasificar se le denomine indización sistemática. Las clasificaciones permiten reducir el mundo multidimensional y polijerárquico del saber a una estructura unidimensional que permita la organización de los documentos en ficheros y estanterías, en bibliografías impresas o en listados sistemáticos de todo tipo.

Este esfuerzo encuentra su justificación en los hábitos de recuperación de los usuarios. En concreto, las principales estrategias de localización de información temática son las tres siguientes, la tercera de las cuales justifica la clasificación:

a) La búsqueda de ejemplares específicos. Se ha calculado que en las bibliotecas académicas el ochenta por cien de los usuarios busca sólo documentos que ya conocía.

b) La búsqueda en el fichero de materias de grupos de documentos sobre un determinado tema.

c) La inspección física de los documentos: mirar las estanterias, los anglosajones la llaman the browsing function (Atkinson, 1990, p. 3). Podemos afirmar que, cuando el usuario tiene necesidades de información que no se traducen en una búsqueda específica, la estrategia de búsqueda por excelencia es la inspección de las estanterías. Es evidente, igualmente, que ante la ausencia de instrumentos de localización de información la estrategia primaria de cualquier usuario es la inspección directa del depósito de documentos y de los propios documentos. En último término cualquier sistema de indización debe considerarse una herramienta de apoyo a esta función básica. Esto es así incluso en nuestros modernos catálogos en línea, donde la inspección del catálogo o del fondo es sustituida por la presentación en pantalla. Por ello, cualquier estrategia que facilite que los libros que tratan sobre lo mismo estén juntos facilitará enormemente la recuperación documental. Esa es precisamente la función de la clasificación, y es

Scire. 2 : 1 (en.-jun. 1996). 
el objetivo último que el clasificador debe perseguir. En este sentido, la clasificación está siendo revitalizada y transformada por el uso de ordenadores, que potencian considerablemente sus posibilidades de recupareración temática. Echar un vistazo a las estanterías está siendo sustituido, cada vez más, por echar un vistazo al catálogo, aunque este tránsito se producirá lentamente y tiene un límite en el gusto del usuario por el contacto con los ejemplares físicos. Con todo, la posiblidad de ojear el catálogo sistemáticamente resulta valiosísima en redes de bibliotecas y catálogos colectivos.

Por último, cuando el usuario tiene necesidad de información muy exhaustiva o ha tenido los consabidos problemas de recuperación — resultados muy pobres o excesivos - la clasificación — gracias a su organización jerárquica— le posibilita, la expansión y reducción controlada de la búsqueda mediante el acceso a niveles superiores e inferiores de la organización conceptual de la unidad de información, y, si conoce bien el esquema de clasificación, unas extraordinarias posiblidades de navegación.

Desde las reflexiones anteriores, parece obvio que la clasificación es sobre todo un sistema de indización, puesto que sitúa cada documento respecto a un instrumento para generar índices sistemáticos, que no otra cosa es una clasificación. No obstante, a pesar de que la mayoría de los autores aceptan esta postura, esta cuestión ha estado sujeta a gran discusión. A partir del experimento de Cranfield la clasificación pasó a considerarse un método más de indización cuyo objetivo es facilitar la recuperación de información (4). Según esta perspectiva, los principios de la recuperación documental se aplican también a la indización precoordinada, y clasificar no es otra cosa que indizar con un lenguaje documental precoordinado (precoordinate indexing language), a saber, un lenguaje de indización cuyos términos pueden ser conectados entre sí mediante recursos sintácticos o sindéticos (Foskett, 1982). Nöe Richter (1990) adopta sin ambagues esta postura en su manual sobre los lenguajes documentarios enciclopédicos. Sin embargo, otros autores como Maniez (1987, trad. esp. 1992, p. 59) defienden, sin embargo, la idiosincrasia de la clasificación como operación documental frente a la indización. Maniez sugiere la utilización del término "caracterización” para referirse al conjunto de ambas operaciones.

No debemos olvidar, sin embargo, que los catalogos automatizados ofrecen también excelentes posibilidades de utilizar la clasificación como lenguaje controlado para la búsqueda postcoordinada. Por otra parte, la vieja oposición entre lenguajes combinatorios — post-coordinables (5) — y clasificatorios — pre-coordinados - en virtud de las posibilidades de combinación mediante un lenguaje de recuperación, va diluyéndose a raíz de las últimas investigaciones sobre recuperación automatizada sobre números de clasificación. McIlwaine (1993, p. 110) en su Guía para el Uso de la CDU indica la posibilidad de indizar separadamente las

Scire. $2: 1$ (en.-jun. 1996). 
distintas facetas de un número de clasificación para permitir las búsquedas postcoordinadas.

\section{El contexto inmediato de la operación de clasificar}

La clasificación como operación es el resultado de un conjunto de elementos que interactúan en función de los objetivos que hemos especificado en el apartado anterior. Dichos elementos son los siguientes: a) la estructura del mundo documental, que constituye tanto la materia como el referente fundamental de la operación documental; b) la clasificación empleada, que constituye el campo representacional de la operación; c) los agentes humanos del proceso de comunicación, fundamentalmente el usuario como receptor y el analista como emisor; y d) el entorno inmediato de la operación, a saber, el propio sistema de información.

\subsection{La estructura del mundo documental}

Es imposible el desempeño correcto de la tarea de clasificar sin la percepción clara de que la clasificación bibliográfica no es arbitraria sino que es una complicada función de nuestra visión de la organización real (empírica) y/o deseada del mundo documental. Podemos ver esas relaciones en el gráfico siguiente (Fig. 8).

Como vimos al principio del artículo, el mundo documental en cuanto que

Realidad
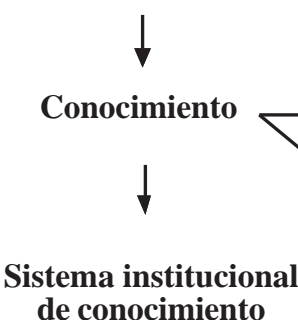

$\downarrow$

Documentos
Usuarios

$\downarrow$

Clasificación empírica del conocimiento

Optimización

Clasificación científicoespeculativa del conocimiento

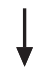

Clasificación

bibliográfica

Fig. 8. Relaciones entre clasificación empírica, especulativa y documental

Scire. $2: 1$ (en.-jun. 1996). 
instrumento comunicativo reproduce el sistema social al que sirve, especialmente las redes e instituciones sociales y científicas. La clasificación documental redibuja esa organización empírica, que sigue las divisiones y subdivisiones del sistema de investigación, de enseñanza y de creación, así como los temas y subtemas de los que se ocupa cada disciplina. De estos aspectos se ocupa una rama de la epistemología científica que se conoce como Sociología de la Ciencia, o Sociología del Conocimiento (6). Sin embargo, la ciencia no sólo se ocupa de estudiar como se organiza la investigación científica, humanística y artística en nuestras sociedades, a saber, el sistema de creacción o producción del conocimiento; sino de como debería organizarse. Las ideas sobre como debería estar organizada la estructura de investigación y enseñanza de las ciencias afecta contínuamente al sistema de producción mismo, y, por ende, a las clasificaciones documentales.

Por supuesto, no debemos creer de forma ingenua que este sistema universal de producción, enseñanza y aprovechamiento del conocimiento — responsable de la producción y uso de los documentos - existe como entidad homogénea y terminada. Del mismo modo que el propio sistema social, está lleno de fracturas y contradicciones, y de variedad y oportunidades de cambio. De esta forma, el sistema documental reproduce la tremenda variedad de nuestras sociedades. Los

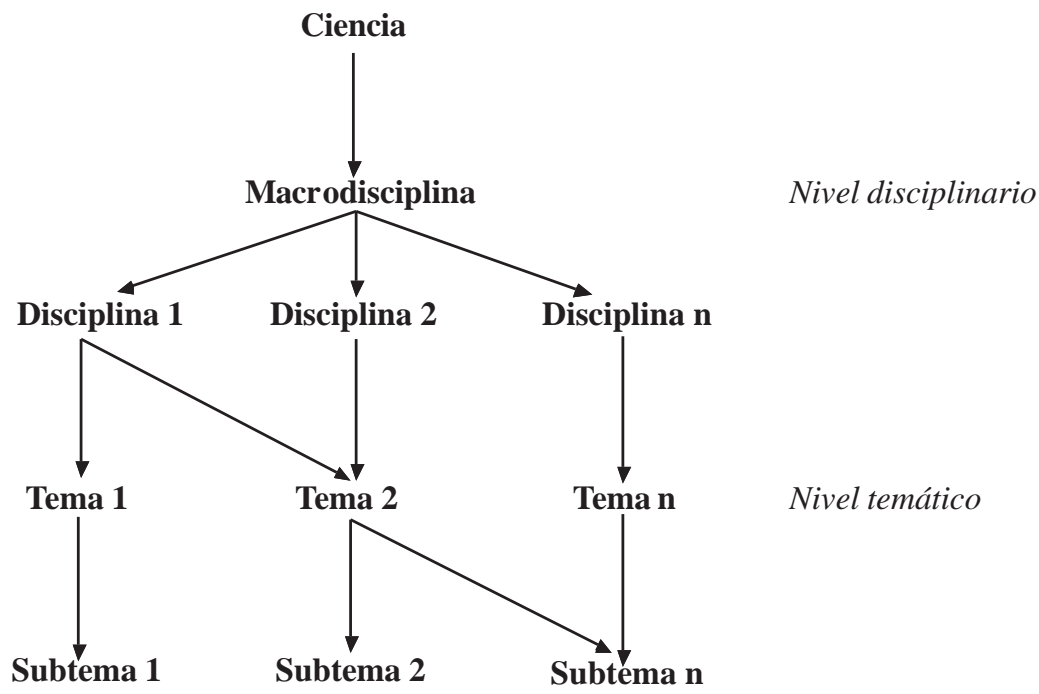

Fig. 10. La organización disciplinaria y temática del conocimiento

Scire. $2: 1$ (en.-jun. 1996). 
autores, por ejemplo, se citan en pequeños grupos denominados "colegios invisibles" que equivalen a escuelas y movimientos de investigación que, normalmente, mantienen relaciones de rivalidad y competencia con otros grupos, y, por supuesto, de cooperación y simbiosis.

El sistema social de producción de conocimiento está organizado en grandes áreas de conocimiento o macrodisciplinas: ciencias exactas, ciencias naturales, ciencias aplicadas, ciencias de la vida, ciencias sociales, humanidades y artes. La macrodisciplinas se subdividen en disciplinas, y éstas en subdisciplinas. Llega un momento en que el nivel institucional desaparece y encontramos lo que denominamos temas. En las artes y en la literatura podemos reconocer lugares comunes, en las humanidades temas de discursión recurrentes (tópicos), y en la ciencia referencias a teorías, principios y "ejemplares compartidos" (Kuhn, 1970) utilizadas por conjuntos de autores. Sin embargo, el mundo de los temas no está ligado biyectivamente al de las disciplinas, sino que cada tema puede ser objeto de una o varias disciplinas, lo cual complica extraordinariamente la clasificación documental (Véase la fig. 9).

En definitiva, la estructura de producción y consumo del conocimiento sirve de macroestructura del mundo documental, y se revela de forma continua en cualquier documento en forma de múltiples referencias y deudas científicas y artísticas, bien se utilicen estos elementos desde el acuerdo bien desde el desacuerdo, ya se construya con ellos o contra ellos. Las clasificaciones documentales y los clasificadores trabajan a partir de esta realidad, adaptándola a las necesidades prácticas de la recuperación documental que hemos estudiado más arriba. El clasificador debe estudiar y dominar el mundo de la producción y consumo de conocimientos como precondición para la correcta clasificación de los documentos que sirven a esta función social.

\subsection{La clasificación documental}

Así pues, las clasificaciones documentales intentan reproducir la organización empírica del sistema de producción y consumo del conocimiento de forma que los documentos sean recuperables bajo la demanda de los usuarios, los consumidores de documentos. Para ello tienen que trasladar la organización multidimensional del mundo del conocimiento al mundo unidimensional del catálogo, del listado o de la estantería. Los distintos tipos de clasificaciones intentan cumplir con mejor o peor fortuna esta misión.

Las clasificaciones suelen categorizarse en dos grandes tipos: las enumerativas y las analítico-sintéticas. Las clasificaciones enumerativas consisten en listados jerárquicos de clases mutuamente excluyentes que no pueden combinarse entre sí. Es decir, cada tema tiene su número en la tabla, y si no, no existe. Son esquemas inflexibles, cuyas tablas tienden a crecer continuamente conforme apa-

Scire. 2 : 1 (en.-jun. 1996). 
recen nuevos temas y, por lo tanto, requieren una larga experiencia en su manejo antes de clasificar correctamente. Las clasificaciones analítico-sintéticas —sean puras, llamadas facetadas, o mixtas, como la CDU- permiten crear nuevos números a partir de los temas reflejados en las tablas, mediante la síntesis entre ellas. Aunque parecen más difíciles al principio, pues exigen un conocimiento perfecto de sus principios teóricos, su uso resulta a posteriori mucho más sencillo y eficaz.

\subsection{El factor humano}

La clasificación es una operación comunicacional que se hace indirectamente - por medio del documento secundario - entre dos agentes humanos: el clasificador y el usuario. Vamos a estudiar en este breve apartado algunas consideraciones generales sobre el factor humano, y a nuestros dos protagonistas:

1. Consideraciones generales sobre el factor humano en la operación de clasificar. Las herramientas teóricas y metodológicas para el estudio del factor humano en el proceso de comunicación documental las aporta la Psicología de la Clasificación y la Lógica de la Clasificación, ramas de la Psicología Cognitiva y de la Epistemología Científica.

A pesar de que, como hemos señalado en el primer apartado de este trabajo, la clasificación es una operación inherente al pensamiento humano; es necesario señalar que la clasificación bibliográfica difiere del mecanismo normal de clasificación que usamos las personas (García y Esteban, 1993). Las investigaciones de Eleanor Rosch (1978) y sus colaboradores demuestran que el mecanismo natural de clasificación humano consiste en fijar un patrón a través del representante ideal de la categoría en cuestión, que luego se aplica a otras entidades del mundo real de forma analógica, en virtud de su semejanza o parecido con el representante de la clase. Sólo cuando existen procesos de discusión intersubjetiva en los que es necesario deslindar claramente si un elemento pertenece $o$ no a una determinada clase, se efectúa una clasificación lógica que genera clases cerradas como las de las taxonomías o las de las propias clasificaciones bibliográficas. La lógica matemática ha incorporado estas investigaciones en una subdisciplina denominada fuzzy logic (lógica difusa). Estas aproximaciones no han producido todavía ningún sistema de clasificación documental que haya superado el estadio de laboratorio. Personalmente, creemos que nunca sustituiran los modelos clasificatorios tradicionales, dada la potencia del cálculo lógico que constituye su fundamento, pero sí que producirán sistemas de ayuda a la recuperación capaces de ajustarse a las necesidades de los usuarios concretos, cosa que los sistemas tradicionales difícilmente pueden conseguir. En definitiva, el uso de clasificaciones requiere un entrenamiento y unos conocimientos que se alejan de nuestro modo innato de pensar, y que sólo la formación puede suplir.

Scire. $2: 1$ (en.-jun. 1996). 
2. El clasificador. No es extraño, a la vista de lo señalado más arriba, que el candidato clasificador debe reunir una serie de requisitos mínimos: a) capacidad de lectura y análisis del contenido; b) buen conocimiento del sistema de clasificación, de su estructura, notación y sintáxis; y c) buen conocimiento de la materia sobre la clasifica, y de aquellas relacionadas con ésta. Todos estos requisitos son igualmente imprescindibles. Es también fundamental un buen conocimiento del tipo de usuarios específicos del centro o servicio para el que se clasifica, y de la política específica de clasificación del centro, cuando el sistema de clasificación permite adaptaciones locales.

Si la clasificación documental tiene como objetivo facilitar la recuperación de la información, el clasificador no debe ser tan sólo un experto en analizar el documento para buscarle un sitio en las estanterías (class and park), sino sobre todo un comunicador que tiende un puente entre el contenido del documento y las necesidades del usuario. El clasificador no trabaja en un puesto de almacenista de libros, sino en un sistema de información. Como señala Atkinson (1990, p. 6) "La tarea del clasificador no termina con el análisis del libro. La clasificación sólo estará completa cuando, además del libro, se hayan analizado sus usos potenciales. Para ello, el clasificador no debe preocuparse sólo de la notación y la memorización de las clases; sino, sobre todo, concentrarse en la organización del esquema global (Atkinson, 1990, p. 11), y en las necesidades de sus usuarios.

La necesidad de conocer en profundidad la materia sobre la que clasifica ha conducido, en algunos sistemas bibliotecarios, a una especialización del trabajo. Así por ejemplo, en Dinamarca, la catalogación es realizada por bibliotecarios generalistas; sin embargo, la clasificación es labor de licenciados o doctores en las correspondientes ramas de la ciencia que han recibido formación en Biblioteconomía y Documentación a nivel de postgrado o master. Esta es una buena medida de optimización de recursos en sistemas bibliotecarios fuertemente integrados, que realizan una catalogación cooperativa o mediante distribuidores - como OCLC o RLIN-.

3. El usuario. Siendo como es la clasificación bibliográfica una actividad mediadora y un servicio, queda claro que el auténtico protagonista de nuestra operación es el usuario: el objetivo de la clasificación es "la ordenación sistemática de los documentos bibliográficos de una forma útil para aquellos que la usan" (Maltby, 1975; ref. Atkinson, 1990, p. 1). Así pues, y como venimos insistiendo, el clasificador debe tener en su mente las necesidades y procedimientos de búsqueda del usuario. Como señala Maltby (1975), en último término, la clasificación bibliográfica sirve para mostrar al usuario una relación entre los documentos que están a su disposición, que de otra manera hubiera pasado desapercibida. La clasificación debe referir al usuario, en primer lugar, a aquellos documentos incluidos en la misma clase, y, en segundo lugar, dirigirle hacia otras clases de la

Scire. 2 : 1 (en.-jun. 1996). 
colección que puedan interesarle, ya sea por ser más genéricas, más especifícas o porque mantengan una cierta relación con el tema que buscábamos en principio.

En teoría, nadie niega que el usuario sea el protagonista de la actividad clasificadora, pero en la práctica esta declaración de intenciones se ha reflejado más bien en la identificación de un conjunto de problemas que en el diseño de soluciones específicas (Younger, 1990). Entre todos esos problemas, el más crítico quizá sea conocer de forma empírica como utilizan nuestros usuarios la colección. Sólo a partir de ese conocimiento será posible iniciar una teoría de la clasificación integrada y auténticamente científica. A partir de este problema básico aparecen una serie de problemas-correlato. Vamos a centrarnos tan sólo en uno de ellos como botón de muestra: ¿existe el usuario? Puede resultar desagradable reconocer que no, pero es el segundo paso — después de reconocer el protagonismo del usuario en la operación de clasificar - para poder comenzar a mejorar nuestros servicios (7). Un primer acercamiento en este sentido, es la clasificación de los usuarios a grandes rasgos en dos grandes grupos - expertos y no-expertos-, junto con una serie de posiciones intermedias a lo largo de una línea continua. El usuario no-experto está interesado, sobre todo, por información bien establecida acerca de un determinado tema. El usuario experto, por su parte, es más exigente y está interesado en: a) comprender las relaciones del documento con los conocimientos que ya posee; y b) especialmente, en la información nueva contenida por el documento. De todos es conocido que los bancos más rentables son los que ofrecen un servicio más personalizado. En definitiva, no hay un usuario, sino muchos distintos; $y$, sin prisa pero sin pausa, hay que salir al encuentro de todos ellos.

\subsection{Las características de la unidad de información}

Queremos apuntar en este apartado algunos aspectos de la unidad de información que condicionan críticamente la ejecución de la operación de clasificar. No vamos a estudiar estos criterios en profundidad puesto que han estado y estarán presentes a lo largo de estas páginas, y su análisis provocaría repeticiones injustificadas. En cualquier caso, las dos variables fundamentales son: a) el tipo de unidad de información — pública y generalista o especializada-; b) el sistema de automatización; c) la pertenecia a redes de información, con las posibilidades parejas de especialización y cooperación; y d) el aumento en el préstamo interbibliotecario y en las posiblidades de autoservicio en este campo por parte del usuario.

En un mundo en cambio y en rápida integración gracias a las tecnologías de la información, la clasificación facilita la presencia de una organización común y de un lenguaje de acceso de carácter internacional, especialmente ante el reto que plantea el proceso de integración-descentralización-especialización que se está

Scire. 2 : 1 (en.-jun. 1996). 
produciendo en la mayor parte de las bibliotecas de los paises desarrollados. Una buena clasificación puede facilitar la especialización de las bibliotecas, la selección de adquisiciones (8), la recuperación en catálogos colectivos distribuidos y la toma de decisiones en redes y sistemas de bibliotecas, por ejemplo, para el análisis de la colección. Por otra parte, el proceso de integración y las facilidades de tele-acceso están ampliando enormemente el mundo de información al que el usuario tiene acceso. Los problemas de especifidad de la búsqueda, bien conocidos en las bibliotecas nacionales con sus millonarias colecciones, se multiplica en el espacio de las redes de bibliotecas, e implica incluso a las bibliotecas más pequeñas. La descentralización y la integración crecientes a nivel nacional e internacional requieren un lenguaje de comunicación común, y uno de esos lenguajes puede ser, por sus especiales características, precisamente la clasificación universal. Como correlato a estos nuevos escenarios bibliotecarios, Atkinson (1990, p. 8) ha llegado a afirmar taxativamente que "la clasificación ha de ser más precisa y mucho más detallada de lo que ha sido hasta ahora".

\section{Conclusiones}

La clasificación es una fase esencial de proceso documental, porque conecta cada documento con el conjunto documental al que pertenece a partir de una organización conceptual previa. En este sentido es a la vez una necesidad y una misión imposible.

Es una necesidad porque el propio sistema cognitivo humano exige la clasificación como condición misma del pensamiento, cuyo objetivo es conseguir una representación integrada del mundo que nos permita realizarnos en él. Por tanto, creemos que la organización de uno de esos nuestros mundos — del mundo documental - resulta sencillamente ineludible, y es necesario enfatizar esta idea programática frente a afirmaciones grautitas vertidas hace no hace tanto tiempo por algunos profetas de los sistemas de recuperación automatizada en texto libre.

Es, sin embargo, una misión imposible porque la clasificación del saber siempre va por detrás del mundo del saber mismo, que, en palabras de Ranganathan, se caracteriza por su dinamismo, su crecimiento continuo en múltiples direcciones, su turbulencia, su multidimensionalidad, su infinitud y su indivisibilidad. La ausencia de organizaciones fuertes que asuman la dirección de esta misión, que requiere tanto esfuerzo y tanta coordinación, ha sido y es una amenaza continua a la obra de los grandes creadores como Dewey, Otlet, La Fontaine, Ranganathan o Bliss, entre otros, que osaron poner manos en una obra tan necesaria como incierta.

En el filo de esta contradicción, el clasificador y el constructor de clasificaciones desarrollan su trabajo con la madurez intelectual del que sabe esforzarse

Scire. $2: 1$ (en.-jun. 1996). 
hasta el límite desde la plena y serena asunción de sus propias limitaciones. Como ha señalado Hugh C. Atkinson (1990, p. 7): "La habilidad para perseguir simultáneamente la perfección y reconocer su incapacidad para conseguirla, mientras se asumen las anomalías de la propia tarea, requiere una fortaleza intelectual que, pienso, los clasificadores siempre han demostrado." Los buenos clasificadores saben que la operación de clasificar admite en su ejecución muchos grados que van desde la chapuza hasta el arte. Saben que la chapuza termina haciendo nuestra tarea irrelevante ante la sociedad. Y saben también, con Atkinson (1990, p. 13) que "cuanto mejor trabajas, más se te demanda". La clasificación es una tarea que puede resultar superficialmente monótona y de utilidad cuestionable, pero que, sin embargo, enfrentada en su dimensión global es profundamente creativa y, ciertamente, ineludible. La indeterminación que le es intrínseca, lejos de hacerla acientífica, la convierte — como a toda verdadera actividad científica- en arte.

\section{Notas}

(1) El problema general de cómo conocemos los seres humanos es objeto de la Psicología, en especial, de la Psicología Cognitiva. Del método científico, en particular, es decir, de la manera en que los científicos conocen, se ocupa la Epistemología científica, una rama de la Filosofía que ha cobrado importancia creciente desde finales del siglo pasado.

(2) Véanse Fugmann (1993), Foskett (1992) O Van Slype (1987) para un análisis exhaustivo de los problemas de los sistemas en texto libre.

(3) El lector puede consultar una excelente reflexión sobre el tema en Frias (1995, p. 146150). El autor propone como criterio prioritario devolver el catálogo al centro de la reflexión informatológica. Efectivamente, el catálogo — la mayor parte de las bases de datos no dejan de ser catálogos- es el instrumento por excelencia de información no sólo en el campo específico de la documentación, sino en todo el mundo del sector servicios.

(4) Véase FOSKETT, 1982, 518 ss.

(5) Preferimos la traducción postcoordinables a postcoordinados, puesto que la postcoordinación no tiene lugar en el propio lenguaje, sino en su utilización posterior.

(6) La investigación en clasificación documental sobre estos temas podría denominarse epistemología social de la clasificación.

(7) Hay posturas fundamentalistas sobre el acceso a la información bibliográfica que pretenden priorizar en exclusiva una información para sectores muy especializados o, al contrario, para la media de la población. Quizá la siguiente reflexión pueda servir de vacuna: La comunidad científica de un país raramente llega al uno por cien de la población total. ¿Se atrevería alguien a decir que no son vitales para el futuro de la comunidad? Viceversa, ¿desearía realmente algún ilustrado en su sano juicio vivir en una sociedad de analfabetos funcionales?

(8) Atkinson (1990, p. 9-10) relata una experiencia de desarrollo cooperativo de colec-

Scire. $2: 1$ (en.-jun. 1996). 
ciones en las bibliotecas de Illinois.

\section{Bibliografía}

Atkinson, Hugh C. (1990).Classification in an unclassified world. En: Bengtson, Betty G. ; Hill, Janet Swan (eds.). Classification of library materials : currrent and future potential for providing access. New York, London : Neal-Shuman Publishers, Inc., 1990. p. $1-15$.

Bengtson, Betty G. ; Hill, Janet Swan (eds.) (1990). Classification of library materials : currrent and future potential for providing access. New York, London : Neal-Shuman Publishers, Inc., 1990.

Cleveland, Donald B.; Cleveland, Ana D. (1983). Introduction to indexing and abstracting. Littleton, Colorado : Libraries Unlimited, UK, 1983.

Cochrane, Pauline A.; Markey, Karen (1985). Preparing for the use of classification in online cataloguing systems and in online catalogues. En: Information Technology and Libraries. N. 4 (1985); p. 91-111.

Fink, Diana Darley ; Tate, John T. Jr. ; Rose, Michael D. (1984). Técnicas de lectura rápida. Madrid : Deusto, 1984.

Foskett, A. C. (1982). The subject approach to information. Fourth ed. London : Clive Bingley ; Hamden Conn, Linnett Books, 1982. Reprinted 1992.

Frías Montoya, José Antonio (1995). Las relaciones entre análisis documental y catalogación: su representación en el plan de estudios de la Universidad de Salamaca. En: García Marco, Francisco Javier (ed.). Organización del Conocimiento en Sistemas de Información y Documentación : actas del I encuentro de ISKO-España, Madrid, 4 y 5 de noviembre de 1993. Zaragoza : Universidad, [etc.], 1995. p. 145-157.

Fugmann, Robert (1993). Subject analysis and Indexing : theoretical foundation and practical advice. Frankfut/Main : Indeks Verlag, 1993.

Fugmman, Robert (1994). Representational predictability : key to the resolution of several pending issues in indexing and information supply. En: Albrechtsen, Hanne ; Oernager, Susanne (1994). Knowledge organization and quality management : Proceedings of the thrid ISKO Conference, 20-24 June 1994, Copenhagen, Denmark [...]. Frankfurt/Main : Indekx Verlag, 1994. p. 414-422.

Garcia Marco, Francisco Javier; Esteban Navarro, Miguel Angel (1993). On some Contributions of the Cognitive Sciences and Epistemology to a Theory of Classification. En: Knowledge Organization. Vol. 20 (1993), n. 3. p. 126-132.

García Marco, Francisco Javier (1995). Criterios de calidad en análisis y representación del contenido: hacia un modelo teórico integrador. En: 5es. Jornades Catalanes de Documentació : biblioteques, centres de documentació i serveis d'informació : 25, 26 i 27 d'octubre de 1995, Palau de Congressos de Barcelona. [Barcelona], D. L. 1995. p. 211-222.

García Marco, Frnacisco Javier (en prensa). La operación de clasificar: consideraciones metodológicas. // Pinto Molina, María. manual de clasificación. Madrid : Síntesis, en prensa.

Scire. $2: 1$ (en.-jun. 1996). 
García Marco, Francisco Javier (en prensa). Clasificación y recuperación de la información. // Pinto Molina, María. manual de clasificación. Madrid : Síntesis, en prensa.

Ghikas, Mary W. (1990). Setting Classification Policy. En: Bengtson, Betty G. ; Hill, Janet Swan (eds.). Classification of library materials : currrent and future potential for providing access. New York, London : Neal-Shuman Publishers, Inc., 1990. p. 126136.

Kuhn, Thomas S.(1970). The structure of scientific revolutions. 2nd., enl. Chicago : The University of Chicago Press, 1970.

Kumar, Krishan (1989). Theory of Classificaction. New Delhi : Vikas, 1989.

Langridge, Derek W. (1992). Classification : its kinds, elements, systems and applications. London : Bowker Saur, 1992.

López Yepes, José (1981). El estudio de la Documentación. Madrid : Editorial Tecnos, 1981.

López Yepes, José (1994). Teoría de la Documentación. 2a ed. Pamplona : Editorial Eunsa, Ediciones Universidad de Navarra, 1994.

López-Huertas Pérez, María José (1995). Metodología para la enseñanza de la CDU a estudiantes de Biblioteconomía y Documentación. En: García Marco, Francisco Javier. Organización del Conocimiento en Sistemas de Información y Documentación: Actas del I Encuentro de ISKO-España, Madrid, 4 y 5 de noviembre de 1993. Zaragoza : Universidad, 1995. P. 173-189.

Maniez, Jacques (1993). Les langages documentaires et classificatoires, Paris: Les éditions d'organisation, 1987, 296 p. Trad. esp.: Los lenguajes documentales y de clasificación : concepción, contrucción y utilización en los sistemas documentales. Madrid ; Salamanca : Fundación Germán Sánchez Ruipérez ; Madrid : Pirámide, 1993.

McIlwaine, I. C. (1994). Guide to the sue of UDC : an introductory guide to the use and application fo the Universal Decimal Classification / by I. C. McIlwaine with participation from A. Buxton. The Hague : International Federation for Information and Documentation, 1993. (FID Occasional Paper ; 5). Trad. esp.: Guía para el uso de la CDU : Clasficación Decimal universal : una guía introductoria para el uso y aplicación de la CDU. Madrid : AENOR, 1994.

Miller, George A. (1956) The magical number seven, plus or minus two : Some limits on our capacity for processing information. In: Psychological Review, n. 63 (1956); p. 81-97.

Pinto Molina, María (1994a). Análisis Documental : fundamentos y procedimientos. 2. ${ }^{a}$ ed. Madrid : Eudema, 1994.

Pinto Molina, María (1994b). Indicadores de calidad descriptiva en la gestión de los procesos analítico-documentales. En: IV Jornadas Españolas de Documentación Automatizada : Documat 94 (Gijón, 6, 7 y 8 de octubre 1994) : Actas : Los profesionales ante el reto del siglo XXI : integración y calidad. Oviedo : Universidad, FESABID, 1994. 189-204.

Ranganathan, S. R. (1967). Prolegomena to library classification. Madras [etc.] : Asia Publishing House, 1967.

Scire. 2 : 1 (en.-jun. 1996). 
Ranganathan, S. R. (1989). Colon Classification : Volume 1 : Schedules for Classification. Edition 7 (Basic and Deth Version) / by S R Ranganathan ; revised and edited by M A Gopinath. Bangalore : Sarada Ranganathan Edowment for Library Science, 1989.

Richedeau, F.; Gauquelin, M. ; Gauquelin, F. (1979). Método de lectura rápida Richaudeau. Madrid : Mensajero, 1979. 283 p.

Richter, Noë (1990). Les languages documentaires encycopédiques : guide pratique d'indexation a à l'usage des documentalistes de l'enseigment et des candidats aux examens et concours des bibliothèques et de la documentation. Le Bourg, Marigné, Éditions de la Queue du Chat, 1990.

Rosch, Eleanor; Lloyd, B.B. (1978). Cognition and Categorisation. Hillsdale : N. J. Lawrence Erlbaum, 1978.

Sánchez Casabón, Ana Isabel (1995). La enseñanza de los lenguajes documentales de estructura jerárquica. En: García Marco, Francisco Javier. Organización del Conocimiento en Sistemas de Información y Documentación: Actas del I Encuentro de ISKO-España, Madrid, 4 y 5 de noviembre de 1993. Zaragoza : Universidad, 1995. p. 191-198.

Taylor, Arlene G. (1990). Classification and copy cataloguing. En: Bengtson, Betty G. ; Hill, Janet Swan (eds.). Classification of library materials : currrent and future potential for providing access. New York, London : Neal-Shuman Publishers, Inc., 1990. p. 81-98.

Van Slype, G. (1991). Les langages d'indexation: conception, construction et utlisation dans les systemes documentaires. Paris : Les éditions d'organisation, 1987. Trad. esp: Los lenguajes de indización: concepción, construcción y utilización en los sistemas documentales. Madrid ; Salamanca : Fundación Germán Sánchez Ruipérez ; Madrid : Pirámide, 1991.

Younger, Jennifer (1990). Classification and the library user. En: Bengtson, Betty G. ; Hill, Janet Swan (eds.). Classification of library materials : currrent and future potential for providing access. New York, London : Neal-Shuman Publishers, Inc., 1990. p. 174-181.

Scire. 2 : 1 (en.-jun. 1996). 